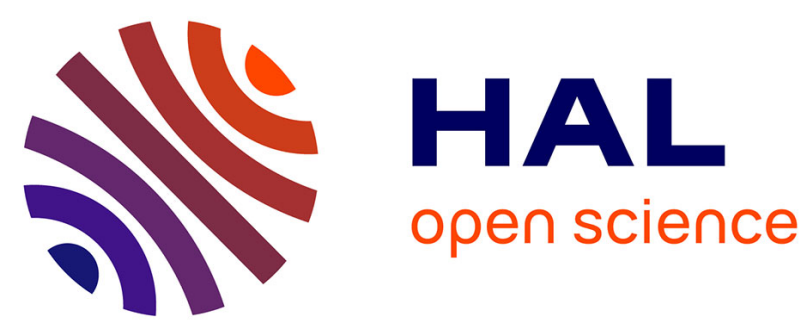

\title{
Polymersome Popping by Light-Induced Osmotic Shock under Temporal, Spatial, and Spectral Control
}

\author{
Ariane Peyret, Emmanuel Ibarboure, Arnaud Tron, Louis Beauté, Ruben \\ Rust, Olivier Sandre, Nathan Mcclenaghan, Sébastien Lecommandoux
}

\section{To cite this version:}

Ariane Peyret, Emmanuel Ibarboure, Arnaud Tron, Louis Beauté, Ruben Rust, et al.. Polymersome Popping by Light-Induced Osmotic Shock under Temporal, Spatial, and Spectral Control. Angewandte Chemie International Edition, 2017, 56 (6), pp.1566-1570. 10.1002/ange.201609231 . hal-01418924

\author{
HAL Id: hal-01418924 \\ https://hal.science/hal-01418924
}

Submitted on 9 Nov 2018

HAL is a multi-disciplinary open access archive for the deposit and dissemination of scientific research documents, whether they are published or not. The documents may come from teaching and research institutions in France or abroad, or from public or private research centers.
L'archive ouverte pluridisciplinaire $\mathbf{H A L}$, est destinée au dépôt et à la diffusion de documents scientifiques de niveau recherche, publiés ou non, émanant des établissements d'enseignement et de recherche français ou étrangers, des laboratoires publics ou privés. 


\title{
Polymersome popping by light-induced osmotic shock under temporal, spatial and spectral control
}

\author{
Ariane Peyret ${ }^{[a]}$, Emmanuel Ibarboure ${ }^{[a]}$, Arnaud Tron ${ }^{[b]}$, Louis Beauté ${ }^{[a]}$, Ruben Rust ${ }^{[b]}$, Olivier Sandre ${ }^{[a]}$, \\ Nathan D. McClenaghan ${ }^{*[b]}$, Sebastien Lecommandoux ${ }^{\star[a]}$
}

\begin{abstract}
A high precision approach allowing light-triggered, programmed cell-sized vesicle rupture is described, with particular emphasis on self-assembled polymersome capsules. The mechanism involves a hypotonic osmotic imbalance created by accumulation of new photogenerated species inside the lumen, which cannot be compensated due to the low water permeability of the membrane. This simple and versatile mechanism can be adapted to a wealth of hydrosoluble molecules, which are either able to generate reactive oxygen species or undergo photocleavage. Ultimately, in a multi-compartmentalized and cell-like system, the possibility to selectively burst polymersomes with high specificity and temporal precision, and consequently deliver small encapsulated vesicles (both polymersomes and liposomes) is demonstrated.
\end{abstract}

Polymersomes are mechanically robust self-assembled vesicular structures that are widely studied and are proving central in increasing research and application areas ranging from nanomedicine to artificial cell design. ${ }^{[1]}$ Control over their membrane diffusion properties and structural integrity is crucial for the development of new complex systems, such as artificial cells. Compartmentalization is central in biological cells. Indeed, physical separation of biochemical species allows metabolic reactions to take place independently and simultaneously in a confined and crowded space. ${ }^{[2-10]}$ For decades, different methods have been proposed to construct elaborate structures that have been developed in the field of lipid and polymer chemistry. ${ }^{[11-14]}$ Amongst others, double emulsion techniques ${ }^{[15-}$ 17], phase transfer of emulsion droplets over an interface ${ }^{[18-20]}$, layer-by-layer assembly ${ }^{[21]}$ or microfluidics ${ }^{[22]}$ have proved efficient in affording micron-sized vesicles, allowing the encapsulation of distinct biochemical species in different compartments and the ability to control simple biomimetic enzymatic reactions in a confined space. ${ }^{[13,23-25]}$

One additional major characteristic of natural cells is their ability to initiate metabolic reactions at a specific time and at a desired location, independently and repeatedly. In this regard, temporal control is crucial in artificial cell systems. However, most of the designed synthetic systems to date lack some control over the initiation of the reactions, which are generally induced by passive diffusion of species across semi-permeable

[a] A. Peyret, E. Ibarboure, L. Beauté, Dr. O. Sandre, Prof. Dr. S. Lecommandoux

Laboratoire de Chimie des Polymères Organiques, LCPO Université de Bordeaux

CNRS, Bordeaux INP, UMR 5629, F-33600 Pessac, France.

E-mail: lecommandoux@enscbp.fr

[b] Dr. A. Tron, R. Rust, Dr. N. D. McClenaghan

Institut des Sciences Moléculaires

Université de Bordeaux

CNRS UMR 5255, 33405 Talence, France.

E-mail : nathan.mcclenaghan@u-bordeaux.fr

Supporting information for this article is given via a link at the end of the document. membranes, either as a result of intrinsic membrane permeability ${ }^{[23]}$ or by the incorporation of channels or pores into the membrane, resulting in a slow release of reactants. ${ }^{[26-28]}$ As a result, a remaining major challenge concerns the ability to trigger specific reactions by selectively and rapidly inducing the release of species from independent compartments, while controlling their concentration. ${ }^{[29,30]}$

Herein, we introduce a tunable protocol for light-driven specific polymersome rupture in time and space, which
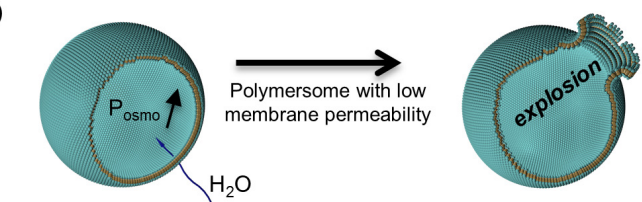

b)
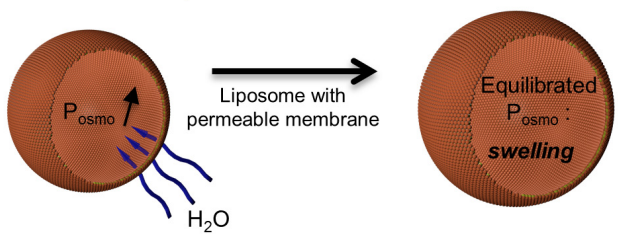

Scheme 1. a) Schematic representation of osmotic pressure increase in polymersomes. The impermeable membrane prevents water from entering the vesicle or the internal solution to leak out and the osmotic pressure remains imbalanced until the vesicle ruptures. b) Schematic representation of osmotic pressure increase in liposomes. The internal osmotic pressure increases transiently but it is rapidly compensated by water diffusion through the tenfold more permeable membrane of the liposome or through sub-critical resealing pores, resulting in vesicle swelling without irreversible rupture.

combines the advantages of utilizing light as a trigger and the fast release of components from bursting vesicles. Our system is based on laser excitation of hydrophilic dyes encapsulated in the lumen of distinct giant poly(butadiene)- $b$-poly(ethylene oxide) (PBut- $b$-PEO) polymersomes, across the whole visible spectrum gamut. Upon excitation the dye is degraded, either through photofragmentation or reactive oxygen species (ROS)-mediated degradation, leading to an increase of the internal osmotic pressure until subsequent polymersome rupture. This process allows for a precise and fast release of entrapped species from different compartments. Additionally, such a selective mechanism allows discrimination between two types of polymersomes within a group of many and to successively trigger the release of their content without altering the remaining vesicles. This system offers great potential for the development of cell mimics where different species encapsulated in distinct organelle-like compartments have to be released independently, in a controlled manner, but also for the release of other (bio)active compounds. 


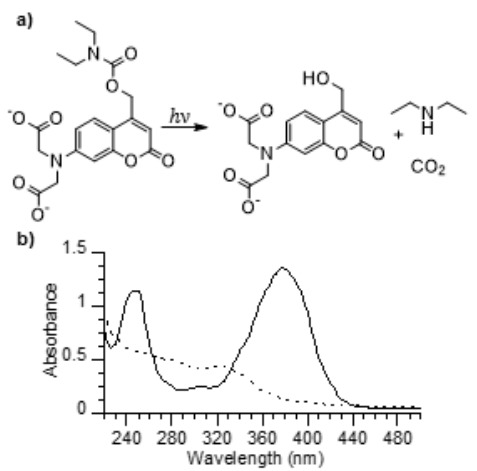

c)

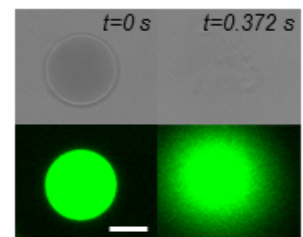

Figure 2. a) Photocleavage of $\mathrm{N}$-diethyl, $\mathrm{O}-(\{7-[\mathrm{bis}$ (carboxymethyl)amino]coumarin-4-yl\}methyl carbamate (coumarin derivative) under irradiation. b) Electronic absorption spectrum of a $80 \mu \mathrm{M}$ coumarin derivative in aqueous solution before and after (dashed line) $30 \mathrm{~min}$ irradiation at $365 \mathrm{~nm}$ with a $200 \mathrm{~W}$ Hg-Xe lamp. c) Confocal observation of a $10 \mathrm{mM}$ coumarin-loaded GUV (green channel, emission range of coumarin, $485 \mathrm{~nm}$ ). The vesicle undergo fast (few milliseconds) rupture upon irradiation at $405 \mathrm{~nm}(50 \mathrm{~mW}, 25 \%)$. Scale bar $=10 \mu \mathrm{m}$.

Poly(butadiene)- $b$-poly(ethylene oxide) $\left(\mathrm{PBut}_{2.5}-b\right.$-PEO $\left.\mathrm{P}_{1.3}\right)$ giant unilamellar vesicles (GUVs) were prepared by a previously reported emulsion-centrifugation method. ${ }^{[31]}$ As suggested in Scheme 1. a), due to the limited water permeability of the polymersome membrane, compared to liposomes, we initially hypothesized that a sudden increase in the internal osmotic pressure of the vesicles would lead to efficient rupture of the membrane. Indeed, water would be unable to diffuse into the cavity fast enough to compensate for the pressure difference between the lumen and the external medium. The outcome is that the membrane is exposed to a large lateral tension and ruptures irreversibly to release pressure. On the other hand, liposomes exhibit a tenfold larger permeability towards water compared to polymersomes (Supplementary Information (SI) p. 14,15), and whenever a pore opens up, the lateral stress on the membrane can be relaxed by hydrodynamic flow from inner to outer solutions through transient pores reported by many groups on large or giant liposomes irrespective of the means used to stress their bilayer: osmotic pressure ${ }^{[32]}$, applied electric field ${ }^{[33]}$, lipid photo-oxidation ${ }^{[34]}$ or membrane dye illumination ${ }^{[35]}$ (Scheme 1. b). Osmotic pressure was also shown to induce shell rupture of layer-by-layer coated gel beads releasing microcapsules. $^{[36]}$ To test our hypothesis, a photodegradation experiment was performed to confirm that fast in situ molecule fragmentation and subsequent osmotic pressure increase in the lumen of giant polymersomes could indeed cause vesicle $\lambda_{\mathrm{exc}}=488 \mathrm{~nm}$ b)
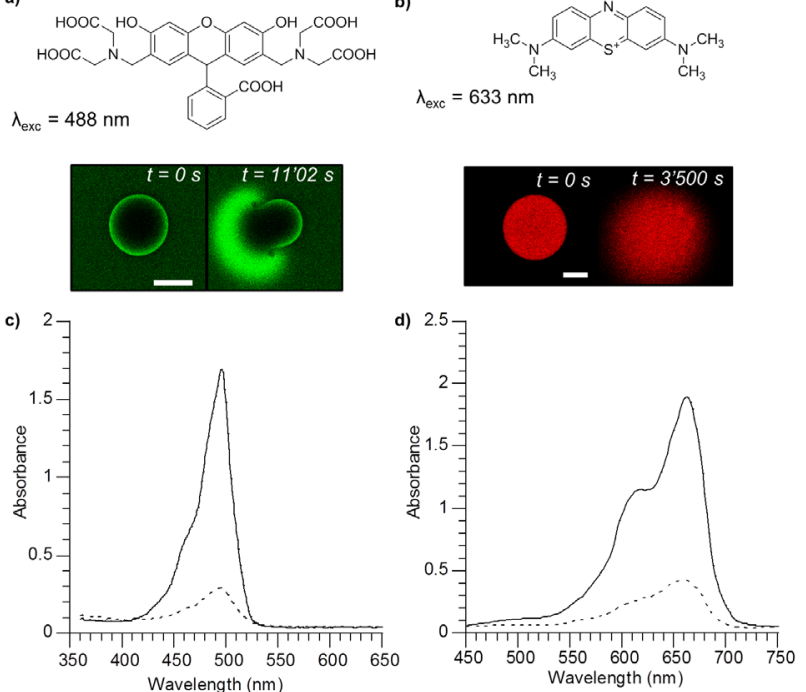

Figure 1. a) Chemical structure of calcein and confocal images of a $15 \mathrm{mM}$ calcein-loaded polymersome irradiated at $488 \mathrm{~nm}$, with laser intensity $40 \mathrm{~mW}, 5 \%$ (green channel, emission range of calcein, $520 \mathrm{~nm}$ ). b) Chemical structure of methylene blue (MB) and confocal images of a $10 \mathrm{mM} \mathrm{MB}$ loaded polymersome irradiated at $633 \mathrm{~nm}$ with laser intensity $10 \mathrm{~mW}, 90 \%$ (red channel, emission range of $\mathrm{MB}, 660 \mathrm{~nm}$ ). c) Electronic absorption spectrum of a $30 \mu \mathrm{M}$ calcein photosensitizer in aqueous solution before and after (dashed line) 30 min irradiation in the $400-550 \mathrm{~nm}$ range with a $200 \mathrm{~W}$ $\mathrm{Hg}-\mathrm{Xe}$ lamp equipped with a bypass filter, showing photoinduced degradation. d) Electronic absorption spectrum of a $30 \mu \mathrm{M}$ methylene blue in water solution before and after (dashed line) 30 min irradiation in the 240 $550 \mathrm{~nm}$ range with a $200 \mathrm{~W} \mathrm{Hg}-X e$ lamp

rupture. In this context, $\mathrm{N}$-diethyl, O-(\{7-[bis(carboxymethyl)amino]coumarin-4-yl\}methyl carbamate (coumarin derivative (11), SI, p. 5-7) was synthesized, inspired by a previously described procedure. ${ }^{[37]}$ It has been established that coumarin derivatives undergo heterolytic $\mathrm{C}-\mathrm{O}$ bond cleavage under UV irradiation. This cleavage results in the formation of a carbamate ion. After decarboxylation of the carbamate, carbon dioxide and diethylamine are released $\left(\Phi_{\text {reaction }}=0.003\right.$ on irradiating at 405 $\mathrm{nm}$ ) (figure 1. a). ${ }^{[38]}$ Cleavage of the molecule was confirmed by a decrease and a shift of the absorption band after 30 min UV irradiation (365 nm, $200 \mathrm{~W} \mathrm{Hg}$-Xe lamp) (figure 1. b). This photoinduced coumarin cleavage feature was used as a way to increase the osmotic pressure inside the polymersomes. The molecule was encapsulated inside the PBut $_{2.5}-b-\mathrm{PEO}_{1.3}$ GUVs. The vesicles were then irradiated under confocal observation (405 nm, $50 \mathrm{~mW}, 25 \%$ ) resulting in a fast (few milliseconds) explosion (figure 1. c). As a control, dye-free (sucrose-loaded) polymersomes were irradiated at $405 \mathrm{~nm}$ and coumarin-loaded polymersomes were irradiated at $488 \mathrm{~nm}$ and $561 \mathrm{~nm}$. In all cases, no rupture was observed, confirming that the explosion results from coumarin selective irradiation. 
a)
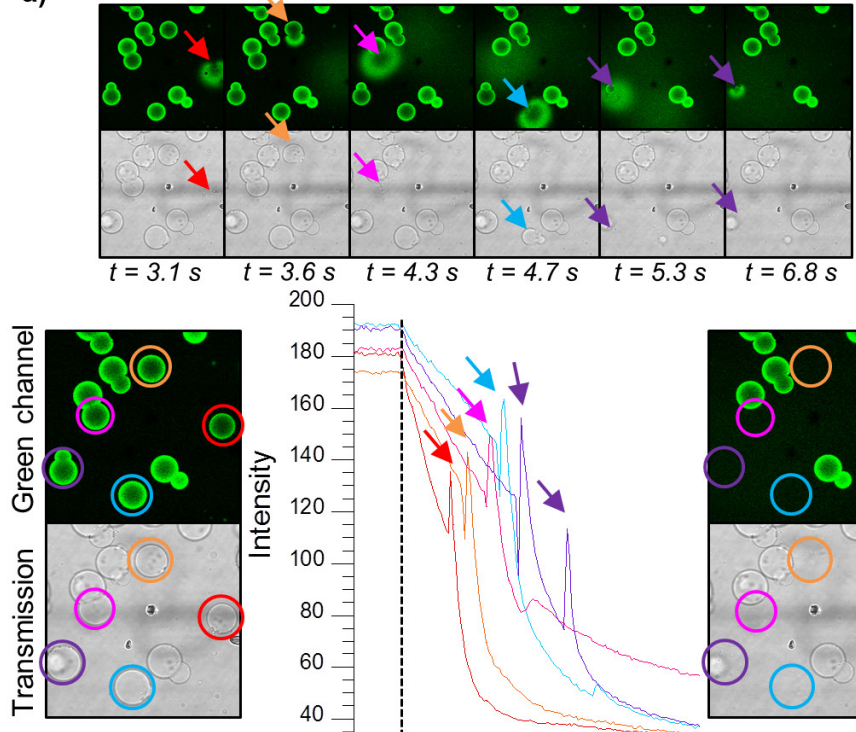

$t=0 \mathrm{~s}$

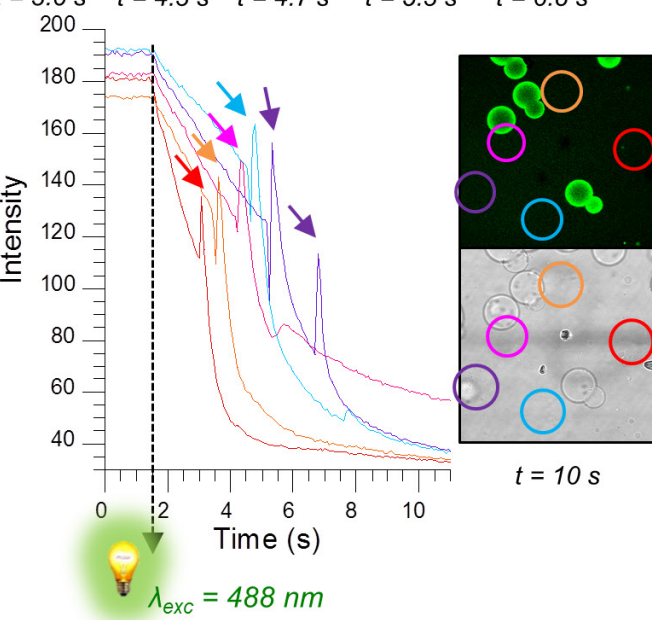

(irradiation of ROIs)

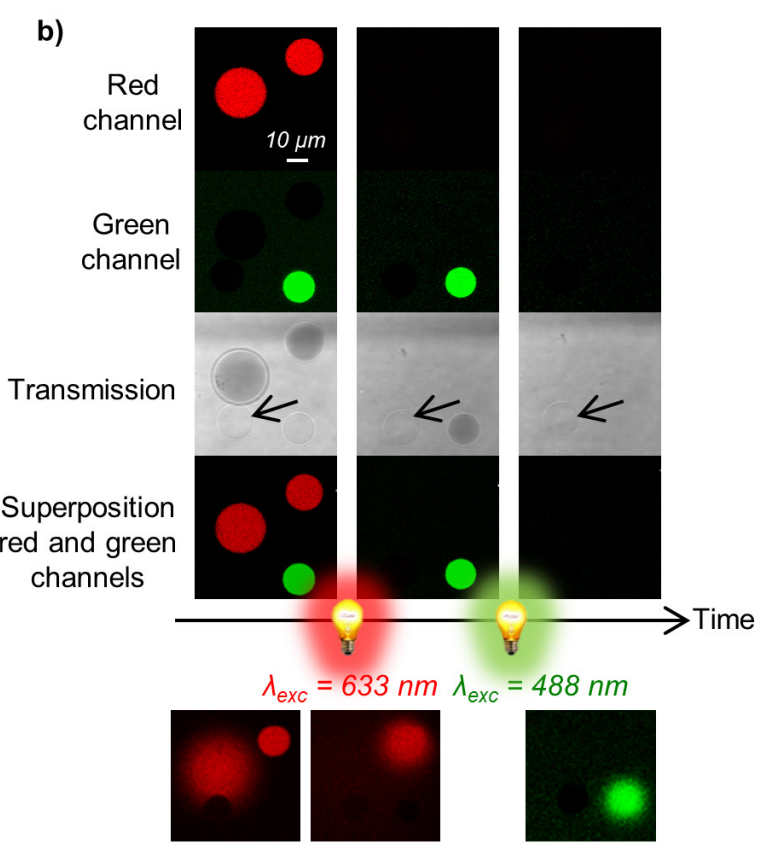

Selective explosion of "red " polymersomes
Selective explosion of " green » polymersomes

Figure 3. Selective rupture of vesicles. a) Time and space. Confocal microscopy observation of 15 mM calcein-loaded PBut $_{2.5}-b$-PEO ${ }_{1.3}$ vesicles. Regions of interest (ROIs) are defined around chosen vesicles (circles) and allow specific irradiation of those vesicles. The fluorescence intensity inside the ROls is monitored over time. At $t=0 \mathrm{~s}, 5$ vesicles (circled) are subjected to high irradiation intensity at $488 \mathrm{~nm}$. Rapid vesicle rupture ( $t=3.1,3.6,4.3,4.7$ and $5.3 \mathrm{~s}$ ) is indicated by a sudden burst in fluorescence intensity (arrows) in the 5 defined ROls. The global decay of fluorescence intensity corresponds to the bleaching of the dye upon irradiation. b) Time and wavelength. Confocal observation of PBut $2.5-b-\mathrm{PEO}_{1.3}$ vesicles loaded with methylene blue (10 mM; red), calcein (15 mM; green) or sucrose $(0.35 \mathrm{M}$; arrow). The first column of pictures shows vesicles subjected to low laser intensity irradiation at $488 \mathrm{~nm}(40 \mathrm{~mW}, 2 \%$, green channel) and $633 \mathrm{~nm}(10 \mathrm{~mW}, 10 \%$, red channel). Then, vesicles are irradiated at $633 \mathrm{~nm}$ (high laser intensity), resulting in a rupture of red vesicles followed by an irradiation at $488 \mathrm{~nm}$ (high laser intensity), provoking rupture of green vesicles. Empty vesicles remain intact as can be seen in the transmission channel. (The movies corresponding to these two series of experiments are presented in SI, video S4 and video S5).

In order to broaden the scope and versatility of the release process, we reasoned that as increased osmolarity is a colligative process, any molecule able to degrade/cleave following illumination would potentially provide a complementary alternative release pathway. In this context, we chose two hydrophilic fluorescent dyes, calcein and methylene blue (MB), that are known to be effective photosensitizers. ${ }^{[39,40]}$ Upon irradiation in the visible region, they generate reactive oxygen species (ROS) including singlet oxygen $\left({ }^{1} \mathrm{O}_{2}\right)$ via energy transfer from the excited triplet state of the dye to the triplet ground state of molecular oxygen $\left({ }^{3} \mathrm{O}_{2}\right) \cdot{ }^{[41]}$ We hypothesized that the fast generation of reactive species upon irradiation would result in increasing the osmotic pressure inside the lumen of the polymersomes and would lead to vesicle bursting. As shown in the confocal images of Figure 2. a), and b), irradiation of GUVs loaded with either $15 \mathrm{mM}$ calcein $\left(\lambda_{\mathrm{exc}}=488 \mathrm{~nm}\right.$, $)$ or $10 \mathrm{mM} \mathrm{MB}$ $\left(\lambda_{\text {exc }}=633 \mathrm{~nm}\right.$,) led to a rapid $(\mathrm{t}<10 \mathrm{~s})$ rupture of the membrane and content release (SI, videos S1, S2). For both dye-loaded vesicles, no bursting occurred on illuminating at wavelengths outside the dye absorption bands, nor for dye-free vesicles (sucrose-loaded only) at any available wavelength (SI, video S3), confirming that the mechanism is not related to direct local heating or any other disturbance of the membrane due to the laser excitation. Further investigation on the exact role of ROS in the overall process showed that ROS are responsible for dye degradation and osmotic pressure increase (SI, p. 8-12). This auto-degradation was evidenced by a decrease of the absorbance of both calcein and MB after 30 min irradiation (Figure 2. c, d) and is considered as the origin of polymersome bursting.

In order to demonstrate the role and versatility of compartmentalization and polymersome explosion in vesiclebased chemical factories or proto-cell design, further series of experiments were conducted. In a first series (Figure 4. a), calcein-loaded PBut $_{2.5}-b-\mathrm{PEO}_{1.3}$ polymersomes were observed with a confocal microscope in bright field (transmission) and in the green channel (emission range of calcein). Regions of interest (ROIs) in the form of circles were defined over several distinct polymersomes. At a defined time, these ROls and consequently the chosen vesicles were subjected to intense irradiation $(488 \mathrm{~nm}, 40 \mathrm{~mW}, 30 \%)$ corresponding to calcein absorption. The fluorescence intensity inside the ROls could be followed during excitation. As shown in a series of snapshot images taken from the videos of the confocal observations, the chosen polymersomes rupture shortly $(\approx 3 \mathrm{~s})$ after being excited. The rupture is associated with the appearance of a peak (arrows) during the fluorescence intensity decay inside the ROIs. This decay corresponds to the bleaching of the dye. Because of 


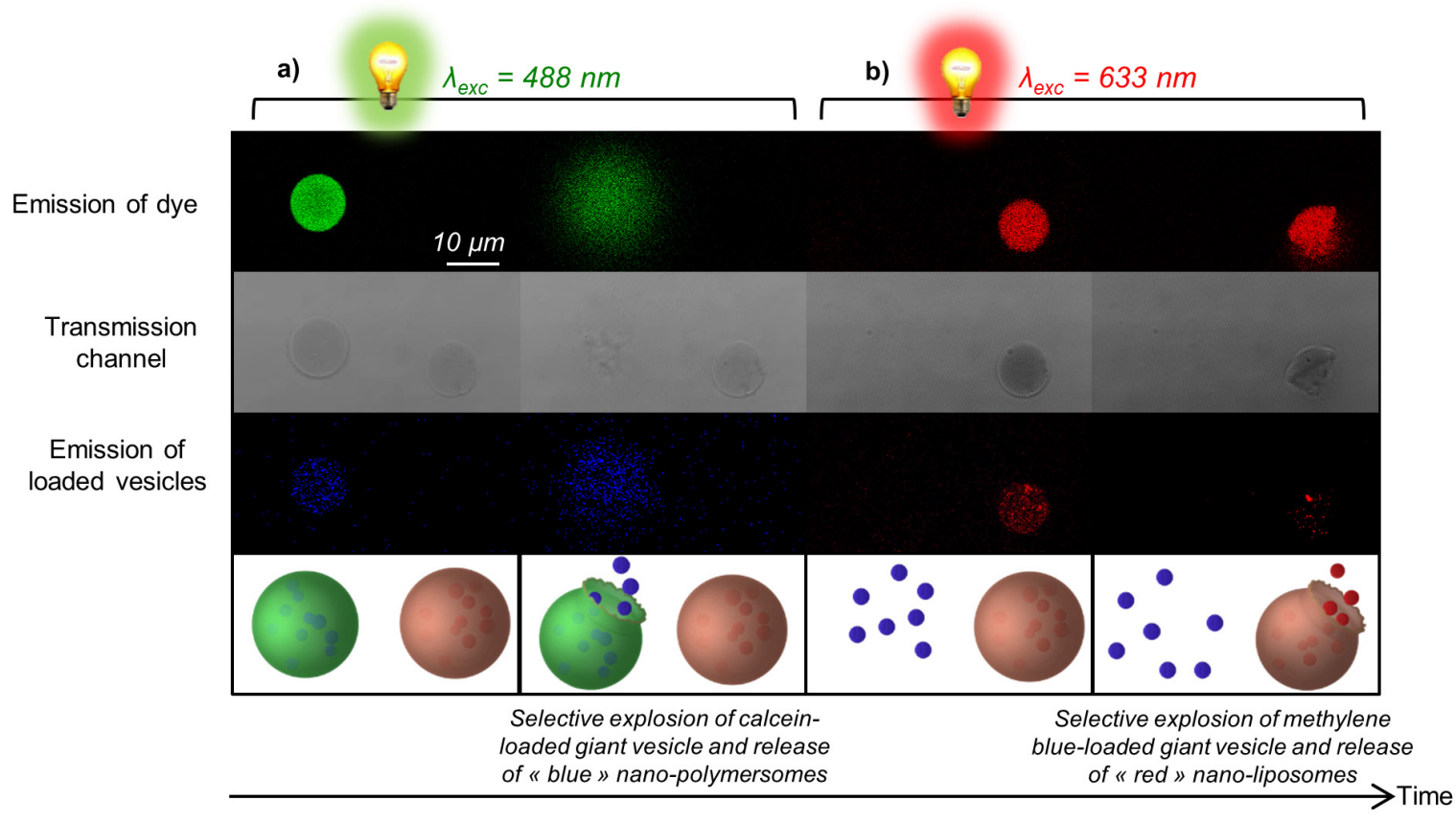

Figure 4. Controlled release of internalized cargo by selective vesicle rupture. Confocal observation of two neighbouring $\mathrm{PBut}_{2.5}-b$ - $\mathrm{PEO}{ }_{1.3} \mathrm{GUV}_{\mathrm{s}}$ loaded

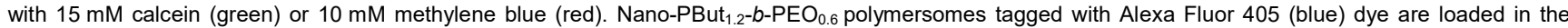
green GUV and nano-DPPC liposomes doped with fluorescent L- $\alpha$-Phosphatidylethanolamine-N-(lissamine rhodamine B sulfonyl) dye (red) are loaded in the red GUV. After a) irradiation at $488 \mathrm{~nm}$ (high laser intensity) the green vesicle ruptures and releases the nano-polymersomes. Then, b) irradiation at $633 \mathrm{~nm}$ (high laser intensity) caused rupture of the red vesicle and subsequent release of the nano-DPPC liposomes. (Movies corresponding to these two series of experiments are presented in SI, video S6).

its high concentration, calcein fluorescence that was initially quenched inside the polymersomes is rapidly recovered when diluted in the external medium due to vesicle rupture (see arrows on Figure 3. a). This method allows fast release of loaded species with high precision in space and time. In another series of experiments, calcein-, methylene blue -loaded and dyefree (sucrose-loaded) giant polymersomes were prepared, mixed together and visualized using confocal microscopy (Figure 3. b). MB-loaded vesicles were visualized in the red channel, calcein-loaded vesicles in the green channel and the native vesicles were only visible in bright field. First, the whole solution was illuminated in the absorption range of MB. As expected, only the red polymersome ruptured while the green and empty ones remained stable. Then, we excited calcein $\left(\lambda_{\mathrm{ex}}=488 \mathrm{~nm}\right)$ and selectively-induced rupture of the green polymersome. The sucrose-loaded vesicles remained stable through the whole process. This method of wavelength selectivity for explosion allows targeting of one or more types of vesicles within a group of many, and to specifically address them.

To illustrate and generalize this last example of controlled species release, an experiment was designed where nanopolymersomes and nano-liposomes (100 nm diameter) were encapsulated separately in PBut $2.5-b-\mathrm{PEO}_{1.3}$ GUVs (Figures $\mathrm{S} 13$ S14). The $\mathrm{PBut}_{1.2}-b-\mathrm{PEO}_{0.6}$ nano-polymersomes tagged with Alexa fluor 405 were encapsulated with calcein in PBut $2.5-b$ $\mathrm{PEO}_{1.3}$ GUVs and the rhodamine tagged 1,2-dipalmitoyl-snglycero-3-phosphocholine (DPPC) nano-liposomes were loaded with $\mathrm{MB}$ in another batch of $\mathrm{PBut}_{2.5}-b-\mathrm{PEO}_{1.3}$ GUVs. Figure 4 shows confocal images of two neighboring GUVs. Visualization in the emission range of Alexa fluor and $L-\alpha$ Phosphatidylethanolamine-N-(lissamine rhodamine B sulfonyl) (blue and red channel respectively) confirmed the effective encapsulation of the nano-vesicles (polymersomes and liposomes) in the cavity of the GUVs. A first irradiation $\left(\lambda_{\mathrm{ex}}=488 \mathrm{~nm}\right)$ triggered selective rupture of calcein-loaded GUVs and a consequent release of $\mathrm{PBut}_{1.2}-b-\mathrm{PEO}_{0.6}$ "blue" nanopolymersomes, as schematically represented in Figure 4 . Then, the sample was irradiated $\left(\lambda_{\mathrm{ex}}=633 \mathrm{~nm}\right)$ to induce the DPPC "red" liposomes release after MB-loaded GUV explosion. This is, to the best of our knowledge, the first reported example of selective triggered release of nano-vesicles (liposomes or polymersomes) loaded in giant polymersomes.

To summarize, photoirradation of vesicles (both polymersomes and liposomes) loaded with photofragmenting dyes (either via the intermediacy of ROS activity or direct photodecaging) is proposed as an efficient external trigger to modulate their membrane properties and structural integrity. Considering much more permeable phospholipid vesicles, the direct consequence of this dye photo-degradation process is vesicle swelling, which renders their membrane more taut (see $\mathrm{SI})$. The ability to tune membrane surface tension of these micron-sized capsules can offer scope in studies of surface tension effect on motility in aqueous solution. Concerning polymersomes, which are much less capable of exchanging water with external bulk solution through passive permeability and cannot open up transiently (due to lower line energy, see SI), an increase in osmolarity accompanying photo-irradiation 
provokes bursting of their membrane, which is shown to release any cargo initially sequestered within the lumen (such as internalized molecules or nano-polymersomes and liposomes). We anticipate that such behavior can be generalized to any other kind of polymersomes or membranes with low water permeability. Additionally, this process is subject to spatial and temporal control based on the appropriate choice of the illumination source and of the irradiation wavelength, depending on the selected photosensitizer, making this phenomenon a universal and versatile approach. Envisioned applications range from directed delivery in nanomedicine, as well as controlled dosing of nutrients and cofactors locally, which may prove decisive in decrypting biochemical interplays in cascade reactions and enzyme function.

\section{Acknowledgements}

This work was funded by the French Ministry of Research and Education (fellow A.P. and A.T.) and the Agence Nationale de la Recherche (ANR program NO-SynthCell N ANR-14-CE160015).

Keywords: polymersomes $\cdot$ photochemistry $\cdot$ photorelease $•$ fluorescence $\bullet$ self-assembly

[1] D. E. Discher, Science 2002, 297, 967-973.

[2] A. H. Chen, P. A. Silver, Trends Cell Biol. 2012, 22, 662670.

[3] Y. Zhang, W. C. Ruder, P. R. LeDuc, Trends Biotechnol. 2008, 26, 14-20.

[4] N. P. Kamat, J. S. Katz, D. A. Hammer, J. Phys. Chem. Lett. 2011, 2, 1612-1623.

[5] A. Pohorille, D. Deamer, Trends Biotechnol. 2002, 20, 123-128.

[6] P. Tanner, S. Egli, V. Balasubramanian, O. Onaca, C. G. Palivan, W. Meier, FEBS Lett. 2011, 585, 1699-1706.

[7] S. Mann, Acc. Chem. Res. 2012, 45, 2131-2141.

[8] J. W. Szostak, D. P. Bartel, P. L. Luisi, Nature 2001, 409, 387-390.

[9] J. Gaitzsch, X. Huang, B. Voit, Chem. Rev. 2016, 116, 1053-1093.

[10] L. Schoonen, J. C. M. van Hest, Adv. Mater. 2016, 28, 1109-1128.

[11] R. Chandrawati, F. Caruso, Langmuir 2012, 28, 1379813807.

[12] R. Chandrawati, M. P. van Koeverden, H. Lomas, F. Caruso, J. Phys. Chem. Lett. 2011, 2, 2639-2649.

[13] M. Marguet, C. Bonduelle, S. Lecommandoux, Chem. Soc. Rev. 2012, 42, 512-529.

[14] W. M. Aumiller Jr, C. D. Keating, Nat. Chem. 2016, 8, 129-137.

[15] A. Perro, C. Nicolet, J. Angly, S. Lecommandoux, J.-F. Le Meins, A. Colin, Langmuir 2011, 27, 9034-9042.
[16] H. C. Shum, Y. Zhao, S.-H. Kim, D. A. Weitz, Angew. Chem. Int. Ed. 2011, 50, 1648-1651.

[17] H.-C. Chiu, Y.-W. Lin, Y.-F. Huang, C.-K. Chuang, C.-S. Chern, Angew. Chem. Int. Ed. 2008, 47, 1875-1878.

[18] E. Mabrouk, D. Cuvelier, F. Brochard-Wyart, P. Nassoy, M.-H. Li, Proc. Natl. Acad. Sci. 2009, 106, 7294-7298.

[19] M. Marguet, L. Edembe, S. Lecommandoux, Angew. Chem. Int. Ed. 2012, 51, 1173-1176.

[20] Y. Elani, A. Gee, R. V. Law, O. Ces, Chem. Sci. 2013, 4, 3332.

[21] L. Hosta-Rigau, S. F. Chung, A. Postma, R. Chandrawati, B. Städler, F. Caruso, Adv. Mater. 2011, 23, 4082-4087.

[22] S.-H. Kim, H. C. Shum, J. W. Kim, J.-C. Cho, D. A. Weitz, J. Am. Chem. Soc. 2011, 133, 15165-15171.

[23] R. J. R. W. Peters, M. Marguet, S. Marais, M. W. Fraaije, J. C. M. van Hest, S. Lecommandoux, Angew. Chem. Int. Ed. 2014, 53, 146-150.

[24] R. J. R. W. Peters, I. Louzao, J. C. M. van Hest, Chem. Sci. 2012, 3, 335-342.

[25] B. Städler, A. D. Price, R. Chandrawati, L. Hosta-Rigau, A N. Zelikin, F. Caruso, Nanoscale 2009, 1, 68-73.

[26] B. Kim, T. Y. Lee, A. Abbaspourrad, S.-H. Kim, Chem. Mater. 2014, DOI 10.1021/cm503831t.

[27] M. Lomora, F. Itel, I. A. Dinu, C. G. Palivan, Phys. Chem. Chem. Phys. 2015, 17, 15538-15546.

[28] Y. Elani, R. V. Law, O. Ces, Nat. Commun. 2014, 5, DOI 10.1038/ncomms6305.

[29] J. Du, R. K. O'Reilly, Soft Matter 2009, 5, 3544-3561.

[30] F. Meng, Z. Zhong, J. Feijen, Biomacromolecules 2009, 10, 197-209.

[31] S. Pautot, B. J. Frisken, D. A. Weitz, Langmuir 2003, 19, 2870-2879.

[32] C. Taupin, M. Dvolaitzky, C. Sauterey, Biochemistry 1975 $14,4771-4775$.

[33] K. A. Riske, R. Dimova, Biophys. J. 2005, 88, 1143-1155.

[34] W. Caetano, P. S. Haddad, R. Itri, D. Severino, V. C. Vieira, M. S. Baptista, A. P. Schröder, C. M. Marques, Langmuir 2007, 23, 1307-1314.

[35] O. Sandre, L. Moreaux, F. Brochard-Wyart, Proc. Natl. Acad. Sci. 1999, 96, 10591-10596.

[36] B. G. De Geest, S. De Koker, K. Immesoete, J. Demeester, S. C. De Smedt, W. E. Hennink, Adv. Mater. 2008, 20, 3687-3691.

[37] W. A. Velema, J. P. van der Berg, W. Szymanski, A. J. M. Driessen, B. L. Feringa, ACS Chem. Biol. 2014, 9, 19691974.

[38] P. Klán, T. Šolomek, C. G. Bochet, A. Blanc, R. Givens, M. Rubina, V. Popik, A. Kostikov, J. Wirz, Chem. Rev. 2013, 113, 119-191.

[39] H. Diehl, J. L. Ellingboe, Anal. Chem. 1956, 28, 882-884.

[40] J. P. Tardivo, A. Del Giglio, C. S. de Oliveira, D. S. Gabrielli, H. C. Junqueira, D. B. Tada, D. Severino, R. de Fátima Turchiello, M. S. Baptista, Photodiagnosis Photodyn. Ther. 2005, 2, 175-191.

[41] C. Beghetto, C. Renken, O. Eriksson, G. Jori, P. Bernardi, F. Ricchelli, Eur. J. Biochem. 2000, 267, 5585-5592. 


\section{COMMUNICATION}

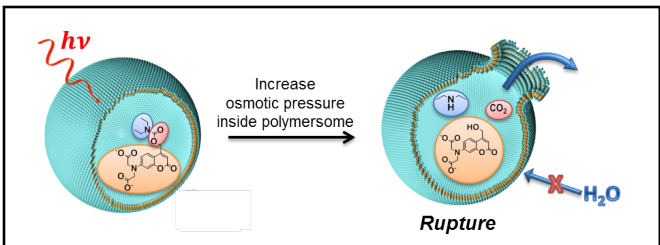

An original and versatile protocol is described for the controlled light-triggered rupture of giant polymersomes. This method allows precise and selective delivery of a range of loaded species with full control in time, space and excitation wavelength.
A. Peyret, E. Ibarboure, A. Tron, L. Beauté, R. Rust, O. Sandre, N. D. McClenaghan*, S. Lecommandoux*

Page No. - Page No.

Polymersome popping by lightinduced osmotic shock under temporal, spatial and spectral control. 


\section{Supporting Information}

\section{Polymersome popping by light-induced osmotic shock under temporal, spatial and spectral control}

Ariane Peyret ${ }^{\mathrm{a}}$, Emmanuel Ibarboure $^{\mathrm{a}}$, Arnaud Tron ${ }^{\mathrm{b}}$, Louis Beaute $^{\mathrm{a}, \mathrm{b}}$, Ruben Rust ${ }^{\mathrm{b}}$, Olivier Sandre $^{\mathrm{a}}$, Nathan D. McClenaghan ${ }^{*}$, , Sébastien Lecommandoux ${ }^{*}$,a

\footnotetext{
${ }^{a}$ Univ. Bordeaux, LCPO, UMR 5629, F-33600, Pessac, France

CNRS, LCPO, UMR 5629, F-33600, Pessac, France

Bordeaux INP, LCPO, UMR 5629, F-33600, Pessac, France

${ }^{\mathrm{b}}$ Institut des Sciences Moléculaires, CNRS UMR 5255, Univ. Bordeaux, 33405 Talence, France.
}

\section{Table of contents}

Page

Supplementary movies S1

Supplementary materials and methods $\mathrm{S} 2-\mathrm{S} 4$

Synthesis of the coumarin derivative (11) S5-S6

Supplementary discussion on the role of ROS

Vesicle swelling and membrane tension rise upon irradiation

Supplementary discussion on membrane pore opening dynamics

\section{List of Supplementary Movies:}

Video S1: bursting of calcein-loaded $\mathrm{PBut}_{2.5}-b-\mathrm{PEO}_{1.3}$ polymersome $(0.35 \mathrm{M}$ sucrose, $30 \mathrm{mM}$ calcein, $\lambda_{\mathrm{ex}}=488 \mathrm{~nm}, 3 \%$ laser intensity).

Video S2: bursting of methylene blue-loaded $\mathrm{PBut}_{2.5}-b-\mathrm{PEO}_{1.3}$ polymersomes $(0.37 \mathrm{M}$ sucrose, $10 \mathrm{mM}$ methylene blue, $\lambda_{\text {ex }}=633 \mathrm{~nm}, 90 \%$ laser intensity).

Video S3: selective explosion of $30 \mathrm{mM}$ calcein-loaded PBut- $b$-PEO polymersomes in the presence of empty ones ( $\lambda_{\mathrm{ex}}=488 \mathrm{~nm}, 3 \%$ laser intensity).

Video S4: spatio-temporal selective rupture of calcein loaded-vesicles.

Video S5: temporal and spectral selective rupture of calcein and methylene blue-loaded vesicles.

Video S6: controlled release of internalized cargo by selective vesicle rupture in time and wavelength. 


\section{Materials:}

Poly(butadiene)- $b$-poly(ethylene oxide) $\mathrm{PBut}_{46}-b-\mathrm{PEO}_{30}$ and $\mathrm{PBut}_{23}-b-\mathrm{PEO}_{14}$ (Mn x $10^{3}$ PBut- $b$-PEO: 2.5- $b$ 1.3 and 1.2-b-0.6; Mw/Mn 1.04 and 1.09) were ordered from Polymer Source (P18422-BdEO and 10191-BdEO batches respectively, both comprising 89\% 1,2-addition of butadiene). 1-Palmitoyl-2oleoyl-sn-glycero-3-phosphocholine (POPC), 1,2-dipalmitoyl-sn-glycero-3-phosphocholine (DPPC) and L- $\alpha$-phosphatidylethanolamine-N-(lissamine rhodamine B sulfonyl) (rhod-PE) were purchased from Avanti Polar Lipids (reference numbers: 850457, 850355 and 810146 respectively). Sodium azide $\left(\mathrm{NaN}_{3}\right)$, sucrose, glucose, calcein, methylene blue and rhodamine were purchased from Sigma Aldrich and used as received. Hydrosoluble caged coumarin and a dibenzofuran-based singlet oxygen trap were synthesized using standard protocols.

\section{Methods:}

NMR experiments were performed at $25{ }^{\circ} \mathrm{C}$ on a Bruker Advance 400 spectrometer operating at 400 $\mathrm{MHz}$ calibrated to the solvent peak in reference to the tetramethylsilane standard. Electronic absorption experiments were carried out on a Varian Cary 5000 UV-vis-NIR spectrophotometer. Mass spectrometry was performed by the CESAMO analytical centre (University of Bordeaux, France) on a QStar Elite mass spectrometer (Applied Biosystems). The instrument is equipped with an ESI source and spectra were recorded in the positive mode. The electrospray needle was maintained at $5000 \mathrm{~V}$ and operated at room temperature. Samples were introduced by injection through a $10 \mu \mathrm{L}$ sample loop into a $200 \mu \mathrm{L} / \mathrm{min}$ flow of methanol from the LC pump. Dynamic Light Scattering (DLS) was used to determine the average size of extruded liposomes and polymersomes in solution. The measurements were performed on a Malvern ZetaSizer Nano ZS instrument with detection at $90^{\circ}$. Samples were analyzed at room temperature. Osmolarity measurements were performed with a freezing point Type$15 \mathrm{M}$ automatic osmometer (Löser, Berlin, Germany). Irradiation experiments were carried with a Mercury-Xenon $200 \mathrm{~W}$ lamp. A filter was used to cut UV light below $400 \mathrm{~nm}$. The wavelength range was $400-550 \mathrm{~nm}$. Samples $(\approx 1-2 \mathrm{~mL})$ were placed $1 \mathrm{~cm}$ from the light guide output end and irradiated in the dark under magnetic stirring for a defined time. Osmolarities were measured before and after irradiation. Viscosities were determined with a DMA generation M density meter equipped with a Lovis $2000 \mathrm{M} / \mathrm{ME}$ rolling ball micro-viscometer from Anton Paar at $20^{\circ} \mathrm{C}$.

Vesicle preparation: Poly(butadiene)- $b$-poly(ethylene oxide) ( $\mathrm{PBut}_{2.5}-b-\mathrm{PEO}_{1.3}$ ) giant polymersomes were prepared by a previously reported emulsion-centrifugation method. Briefly, $5 \mu \mathrm{L}$ of sucrose 0.38 $\mathrm{M}$ was poured into $3 \mathrm{mg} / \mathrm{mL} \mathrm{PBut}_{2.5}-b-\mathrm{PEO}_{1.3}$ in $500 \mu \mathrm{L}$ toluene. The solution was vigorously handshaken for 30 seconds to create a water-in-oil emulsion. An interface was prepared by pouring $30 \mu \mathrm{L}$ of PBut $_{2.5}-b-\mathrm{PEO}_{1.3}(3 \mathrm{mg} / \mathrm{mL})$ in toluene over $30 \mu \mathrm{L}$ glucose $0.38 \mathrm{M}$ and allowed to stabilize for 30 minutes. $60 \mu \mathrm{L}$ of the above emulsion was slowly poured over the interface and the sample was immediately centrifuged ( $3 \mathrm{~min}, 500 \mathrm{~g}$, ambient temperature). The resulting polymersomes were 
recovered in the lower phase. In the case of calcein or methylene blue (MB)-loaded polymersomes, the dye was dissolved in a sucrose solution to reach the desired concentration and $5 \mu \mathrm{L}$ of this solution was used to form the emulsion. The concentration of glucose was adjusted to the same osmotic pressure as the dye in sucrose solution. For the ROS quenching experiment with sodium azide $\left(\mathrm{NaN}_{3}\right)$, the desired concentration of $\mathrm{NaN}_{3}$ was added to the calcein in sucrose solution and $5 \mu \mathrm{L}$ of this solution was used to form the emulsion. The concentration of glucose was adjusted to the same osmotic pressure (sucrose and dye-containing solution).

Confocal microcopy observations: Laser scanning confocal microscopy images were acquired on an inverted Leica TCS SP5 microscope equipped with an HCX PL APO 63×, NA 1.4 oil immersion objective in fluorescence mode. Samples $(\approx 20 \mu \mathrm{L})$ were injected in a homemade chamber that was sealed to prevent evaporation. The laser outputs were controlled via the Acousto-Optical Tunable filter (AOTF) and the two collection windows using the Acousto-Optical Beam Splitter (AOBS) and photomultipliers (PMT) as follows: Alexa Fluor 405 was excited with a diode laser at $405 \mathrm{~nm}$ and measured with emission settings at 415-455 nm, calcein was excited with an argon laser at $488 \mathrm{~nm}$ (3$20 \%$ ) using a 418-423 nm window, rhodamine was excited at $561 \mathrm{~nm}$ using a 575-600 nm window and MB was excited at $633 \mathrm{~nm}$ with emission settings at 650-700 $\mathrm{nm}(90 \%)$. The Helium-Neon laser at 633 $\mathrm{nm}(10 \%)$ was also used in transmission mode. Images were collected in simultaneous mode using a resonant scanner at $8000 \mathrm{~Hz}$ in bidirectional mode at a resolution of either $512 \times 512,1024 \times 1024$ or $1024 \times 256$ pixels. For the pore opening measurements, a lower resolution was used $(128 \times 128)$ to acquire 1 frame/10ms. The FRAP wizard using the fly mode for faster time resolution was used to define regions of interest (ROIs) around chosen vesicles. Processing of fluorescence confocal acquisitions was performed with the ImageJ freeware.

Gel assisted giant unilamellar vesicle (GUV) formation: Giant liposomes were prepared by spin-coating and film rehydration on polyvinyl alcohol (PVA, Mw=143000 g. $\mathrm{mol}^{-1}, 100 \%$ hydrolyzed, Merck S6585 194 247) gel. ${ }^{[1]}$ A few drops of $30 \mathrm{mM}$ calcein in $5 \%$ PVA solution in water (pH adjusted to 7.4) were spin coated on a microscope coverslip (2500 rpm, 3 minutes). 1-Palmitoyl-2-oleoyl-sn-glycero-3phosphocholine (POPC) lipids $(1 \mathrm{mg} / \mathrm{mL})$ tagged with rhod PE and dissolved in chloroform were spread out on the dried calcein-PVA film. After solvent evaporation, small chambers were formed and filled with $1 \mathrm{~mL}$ sucrose solution $(0.35 \mathrm{M})$. GUV formation was followed under the confocal microscope (bright field). Glass micropipettes used to aspire the GUVs were prepared using a pipette puller (from Sutter Instrument: Model P97) followed by micro-forge treatment of the tip to adjust the inner diameter of the capillary around 5-10 $\mu \mathrm{m}$. A micromanipulator (Eppendorf PatchMan NP2) 
connected to a water reservoir was used to move the micropipette. A micrometer allowed both to move the water reservoir with precision and to measure the low pressures applied to the aspired GUVs.

Photocapture of singlet oxygen: Photocapture of singlet oxygen was determined upon excitation at 488 $\mathrm{nm}$ (calcein) or $633 \mathrm{~nm}$ (methylene blue) on an optical bench equipped with a $150 \mathrm{~W} \mathrm{Hg-Xe} \mathrm{lamp} \mathrm{and} \mathrm{a}$ monochromator. Samples (ratio fluorescent dye/oxygen trap : $10 \mu \mathrm{M} / 40 \mu \mathrm{M}$ in sucrose $0.35 \mathrm{M}$ ) were stirred during the irradiation and the amount of converted material was determined by UV-visible spectroscopy following the disappearance of the absorption band of the oxygen trap at $425 \mathrm{~nm}$.

Small unilamellar liposome/polymersome preparation and incorporation in giant polymersomes: Liposomes were prepared by the thin film rehydration method, followed by extrusion. 1,2-Dipalmitoyl$s n$-glycero-3-phosphocholine (DPPC) lipids $(6 \mathrm{mg} / \mathrm{mL})$ and L- $\alpha$-phosphatidylethanolamine-N(lissamine rhodamine B sulfonyl) (rhod PE) $(0.1 \mathrm{mg} / \mathrm{mL})$ were solubilized in chloroform. $1 \mathrm{~mL}$ of the above solution was evaporated on a rotary evaporator and rehydrated under magnetic stirring with 1.5 $\mathrm{mL}$ milliQ water $\left(50^{\circ} \mathrm{C}\right.$, overnight). The resulting suspension was extruded (Avanti Mini-Extruder, Avanti Polar Lipids) through a $400 \mathrm{~nm}$ poly-carbonate filter. For the encapsulation in the giant polymersomes, the vesicle preparation protocol was followed. $15 \mu \mathrm{L}$ of the liposomes suspension was added to $15 \mu \mathrm{L}$ of $30 \mathrm{mM}$ calcein in sucrose $0.35 \mathrm{M}$ and $5 \mu \mathrm{L}$ of this solution was used to form the emulsion. The concentration of the glucose solution for the interface was adjusted to the same osmotic pressure as the liposomes in calcein-sucrose solution. The same procedure was applied to form PBut- $b$ PEO (Mn x 10 $\left.0^{3}: 1.2-b-0.6\right)$ polymersomes with $\approx 3$ wt. \% PBut $\left(\mathrm{Mn}=1700 \mathrm{~g} \cdot \mathrm{mol}^{-1}\right)$ tagged with Alexa Fluor 405. ${ }^{[2]}$ 


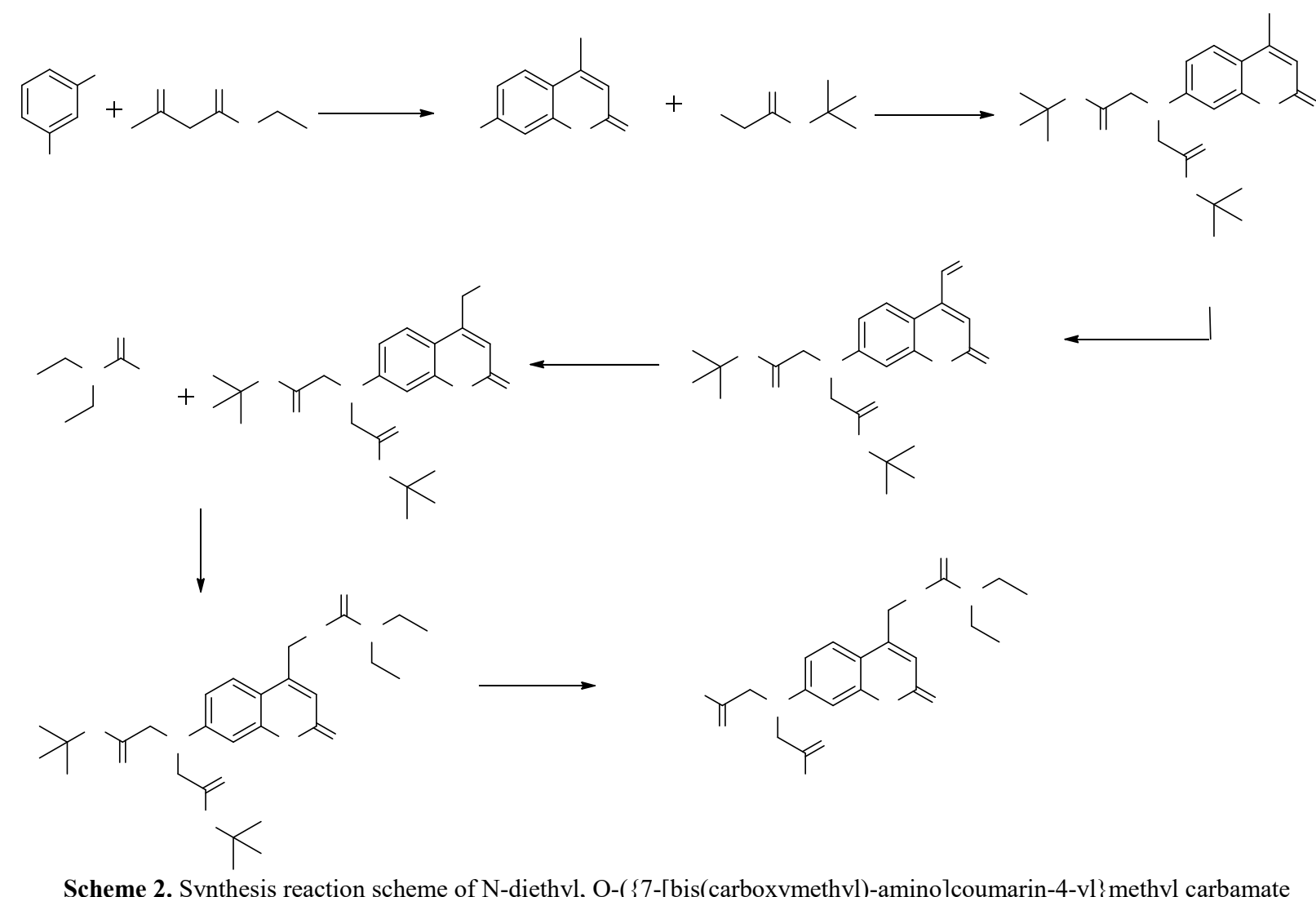

The synthesis protocol was adapted from literature procedures for a structurally-related photoactive conjugate. $^{[3,4]}$

7-amino-4-methylcoumarin (6): Ethyl acetoacetate (45.8 $\mathrm{mmol}, 1 \mathrm{eq})$ was added to a mixture of 3aminophenol $(45.8 \mathrm{mmol}, 1 \mathrm{eq})$ and $\mathrm{Y}(\mathrm{NO} 3)_{3} \cdot 6 \mathrm{H}_{2} \mathrm{O}(4.58 \mathrm{mmol}, 0.1 \mathrm{eq})$ in a $100 \mathrm{~mL}$ round bottom flask. The reaction mixture was stirred at $90^{\circ} \mathrm{C}$ for 2 hours. The mixture was dispersed in water and the solid was filtered. The resulting crude product was then recrystallized from EtOH to give a yellow/green crystalline powder $(50 \%$ yield $)$.

${ }^{1}$ H NMR (DMSO, 300 MHz) $\boldsymbol{\delta}$ (ppm): 7.41 (d, 1H), 6.57 (dd, 1H), 6.41 (d, 1H), 6.12 (s, 2H), 5.91 (s, $1 \mathrm{H}), 3.35(\mathrm{~s}, 1 \mathrm{H}), 2.31(\mathrm{~s}, 3 \mathrm{H})$.

Di-tert-butyl 2,2'-((4-methyl-2-oxo-2H-chromen-7-yl)azanediyl)diacetate (7): Compound 6 (22.8 mmol, 1eq) was dissolved in $\mathrm{MeCN}(120 \mathrm{~mL})$ in a round-bottom flask of $250 \mathrm{~mL}$ and then $t$ butylbromoacetate (114 mmol, $5 \mathrm{eq}), \mathrm{NaI}$ (45.4 mmol, 2eq) and DIPEA (91 mmol, 4eq) were added. The mixture was heated at reflux for 3 days. Then the mixture was concentrated in vacuo and the residue was dissolved in EtOAc $(100 \mathrm{~mL})$ and washed with water $(100 \mathrm{~mL})$ and brine $(100 \mathrm{~mL})$ and dried over $\mathrm{MgSO}_{4}$. Following purification by column chromatography on silica gel (cyclohexane/EtOAc, 5:1) and solvent removal, an orange solid was obtained (25\% yield).

${ }^{1}$ H NMR (DMSO, 300 MHz) $\delta$ (ppm): 7.57 (d, 1H), 6.58 (dd, 1H), 6.43 (d, 1H), 6.05 (d, 1H), 4.19 (s, $4 \mathrm{H}), 2.36(\mathrm{~d}, 3 \mathrm{H}), 1.43(\mathrm{~s}, 18 \mathrm{H})$.

Di-tert-butyl 2,2'-((4-formyl-2-oxo-2H-chromen-7-yl)azanediyl)diacetate (8): Selenium dioxide (10.9 mmol, 2eq) was added to a solution of compound 7 (5.45 mmol, 1eq) in $p$-xylene $(55 \mathrm{~mL})$. The resulting mixture was heated at reflux for $16 \mathrm{~h}$ and filtered while hot. The filtrate was concentrated in vacuo yielding a dark orange solid (94\%).

${ }^{1}$ H NMR (DMSO, 300 MHz) $\delta$ (ppm): 10.10 (s, 1H), 8.25 (d, 1H), 6.78 (s, 1H), $6.66(\mathrm{dd}, 1 \mathrm{H}), 6.53$ (d, $1 \mathrm{H}), 4.22(\mathrm{~s}, 4 \mathrm{H}), 1.44(\mathrm{~s}, 18 \mathrm{H})$. 
Di-tert-butyl 2,2'-((4-(hydroxymethyl)-2-oxo-2H-chromen-7-yl)azanediyl)diacetate (9): Compound 8 (4.8 mmol, 1 eq) was dissolved in a mixture of methanol $(50 \mathrm{~mL})$ and THF $(50 \mathrm{~mL})$ and the solution was cooled on ice. $\mathrm{NaBH}_{4}(7.2 \mathrm{mmol}, 1.5 \mathrm{eq})$ was added in small portions and the reaction mixture was stirred for $3 \mathrm{~h}$. After this time, the reaction was quenched by addition of $1 \mathrm{~N}$ aqueous $\mathrm{HCl}(20 \mathrm{~mL})$ and the mixture was extracted twice with EtOAc. The combined organic layers were washed with brine and dried $\left(\mathrm{MgSO}_{4}\right)$. The product was purified by column chromatography over silica gel (cyclohexane:AcOEt; $1: 1 \mathrm{v} / \mathrm{v}$ ) and resulted in a green solid (40\% yield).

${ }^{1}$ H NMR (DMSO, 300 MHz) $\delta$ (ppm): 7.50 (d, 1H), 6.55 (dd, 1H), 6.45 (d, 1H), 6.16 (s, 1H), 5.56 (t, $1 \mathrm{H}), 4.70(\mathrm{~d}, 2 \mathrm{H}), 4.19(\mathrm{~s}, 4 \mathrm{H}), 1.43(\mathrm{~s}, 18 \mathrm{H})$.

Di-tert-butyl

2,2'-((4-((diethylcarbamoyl)oxy)methyl)-2-oxo-2H-chromen-7-

yl)azanediyl)diacetate (10): Diethylcarbamoyl chloride $(0.5 \mathrm{~mL}$, excess) was added to a solution of compound $9(0.24 \mathrm{mmol}, 1 \mathrm{eq})$ in pyridine $(3 \mathrm{~mL})$ at ambient temperature. Then the mixture was heated to $90^{\circ} \mathrm{C}$ for 48 hours under a nitrogen atmosphere. After the reaction mixture was cooled to ambient temperature, $1 \mathrm{~N} \mathrm{HCl}$ was added and the mixture was extracted with EtOAc. The combined organic layers were washed with saturated $\mathrm{NaHCO}_{3}$ solution and concentrated. Then the crude product was purified by silica column chromatography, eluting with cyclohexane:EtOAc $(5: 1, v / v)$ yielding the product (40\% yield) upon solvent removal.

${ }^{1}$ H NMR (CDCl 3 , 300 MHz) $\boldsymbol{\delta}$ (ppm): $7.40(\mathrm{~d}, 1 \mathrm{H}), 6.54(\mathrm{~m}, 2 \mathrm{H}), 6.24$ (s, 1H), 5.29 (d, 2H), 4.09 (s, $4 \mathrm{H}), 3.38$ (q, 4H), $1.52(\mathrm{~s}, 18 \mathrm{H}), 1.2(\mathrm{t}, 6 \mathrm{H})$.

$\left.{ }^{13} \mathbf{C ~ N M R ~ ( C D C l}_{3}, 400 \mathrm{MHz}\right) \boldsymbol{\delta}$ (ppm): 167.9, 160.7, 154.6, 153.8, 150.2, 149.5, 123.5, 108.1, 107.3, 106.8, 98.2, 81.5, 61.1, 53.3, 41.2, 40.4, 28.7, 27.1, 13.1, 13.4.

MS-TOF: $\mathrm{m} / \mathrm{z}=541.2520$ calculated for $\mathrm{C}_{27} \mathrm{H}_{38} \mathrm{~N}_{2} \mathrm{O}_{8} \mathrm{Na} ; \mathrm{m} / \mathrm{z}=541.2504[\mathrm{M}+\mathrm{Na}]^{+}$

2,2'-((4-(((diethylcarbamoyl)oxy)methyl)-2-oxo-2H-chromen-7-yl)azanediyl)diacetic acid (11) : Compound $10(0.058 \mathrm{mmol}$, 1eq) was dissolved in THF $(0.5 \mathrm{~mL})$. Then $0.13 \mathrm{~mL}$ of a water solution containing $100 \mathrm{mg}$ of $\mathrm{KOH}$ in $1 \mathrm{~mL}$ of water was added $(\mathrm{KOH}=4 \mathrm{eq})$. The mixture was stirred at room temperature overnight. Water and THF were removed and the product was dissolved in water and precipitated on adding a small amount of $\mathrm{HCl}$ until precipitate formation was complete. The product, which was a red powder, was filtered off and dried in vacuo (50\% yield).

${ }^{1}$ H NMR (DMSO, $\left.600 \mathrm{MHz}, \mathbf{6 0}^{\circ} \mathrm{C}\right) \boldsymbol{\delta}$ (ppm): $7.53(\mathrm{~d}, 1 \mathrm{H}), 6.64(\mathrm{dd}, 1 \mathrm{H}), 6.5(\mathrm{~d}, 1 \mathrm{H}), 6.01(\mathrm{~s}, 1 \mathrm{H})$, $5.28(\mathrm{~s}, 2 \mathrm{H}), 4.22(\mathrm{~s}, 4 \mathrm{H}), 3.31(\mathrm{q}, 4 \mathrm{H}), 1.12(\mathrm{t}, 6 \mathrm{H})$.

${ }^{13}$ C NMR (MeOD, 400 MHz) $\delta$ (ppm): 175.8, 162.3, 155.6, 155.2, 152.0, 150.7, 125.0, 109.0, 107.7, 106.4, 98.0, 62.1, 56.3, 41.9, 41.3, 13.0, 12.2 .

TOF-MS $[\mathbf{M}-\mathbf{H}]^{+}: \mathrm{m} / \mathrm{z}=405.1303$ calculated for $\mathrm{C}_{19} \mathrm{H}_{21} \mathrm{~N}_{2} \mathrm{O}_{8} ;$ Found: $\mathrm{m} / \mathrm{z}=405.1301$ 


\section{Supplementary discussion: ROS involvement in the photosensitizer degradation process}

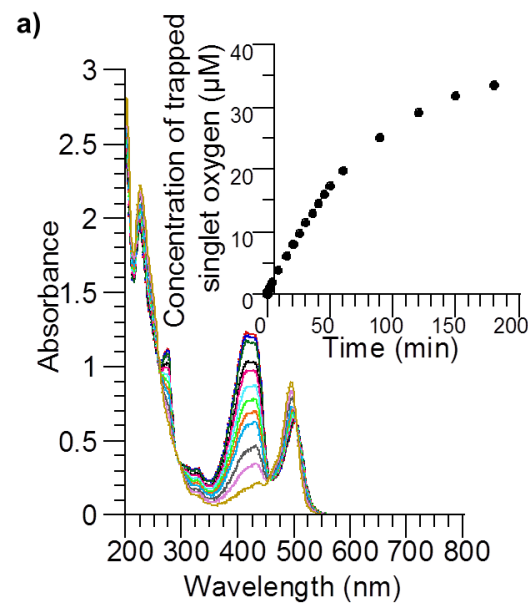

b)

1.

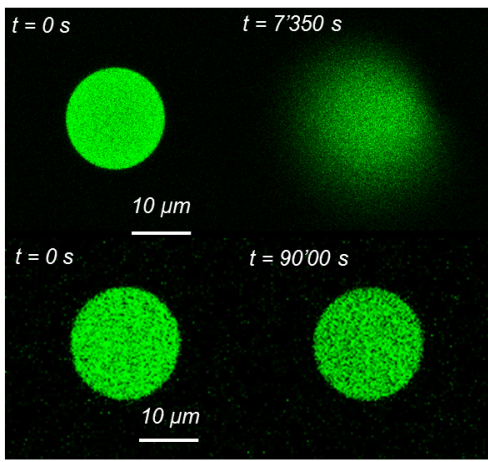

Figure S 1. a) UV-visible absorption spectra of a solution of calcein $\left(\lambda_{\max }=488 \mathrm{~nm}\right)$ and singlet oxygen scavenger $\left(\lambda_{\max }=425 \mathrm{~nm}\right)(\mathrm{ratio}$ 1:4) during irradiation at $488 \mathrm{~nm}$ and singlet oxygen consumption over time. The decrease of the absorption of the scavenger indicates the consumption of singlet oxygen during irradiation. b) Confocal images of $5 \mathrm{mM}$ calcein-loaded $\mathrm{PBut}_{2.5}-b-\mathrm{PEO}_{1.3}$ polymersomes during irradiation $(488 \mathrm{~nm}) 1$. without and 2. with 3 eq. sodium azide $\left(\mathrm{NaN}_{3}\right) . \mathrm{NaN}_{3}$ efficiently prevents vesicle rupture (verified on $\left.\sim 15 \mathrm{vesicles}\right)$.

To further understand the mechanism of vesicle bursting at the molecular level, we investigated the role of ROS production in the overall phenomenon. We first evaluated the generation of ROS using a scavenger for singlet oxygen $\left({ }^{1} \mathrm{O}_{2}\right)$, known to be predominantly generated by excited calcein in the presence of oxygen. ${ }^{[5]}$ The scavenger is a hydrophilic derivative of 1,3-diphenylisobenzofuran (DPBF), used for the detection of ${ }^{1} \mathrm{O}_{2}$ in vitro. ${ }^{[6]}$ A mixture of calcein in sucrose was prepared with a four-fold excess of the scavenger. The evolution of the absorption band of the scavenger was followed spectrophotometrically during excitation of the solution at $488 \mathrm{~nm}$ on an optical bench (Figure S 1. a). The disappearance of the main emission band at $425 \mathrm{~nm}$ (arrow) as a function of illumination time, which is directly correlated with the consumption of ${ }^{1} \mathrm{O}_{2}$, confirmed that ROS were effectively generated by calcein upon irradiation. If ROS generation is part of the process leading to membrane rupture, then the use of a scavenger should prevent vesicles from bursting, as confirmed in Figure $\mathbf{S} \mathbf{1}$. b using sodium azide $\left(\mathrm{NaN}_{3}\right)$ as a ${ }^{1} \mathrm{O}_{2}$ quencher. ${ }^{[7]}$ Under the same irradiation conditions, explosion was inhibited by the presence of the oxygen scavenger, meaning that the scavenger efficiently trapped the generated singlet oxygen. In order to evaluate the consequence of singlet oxygen generation on the osmotic pressure change, a solution of calcein in sucrose (at varying concentration) was prepared at the same concentration as that used in polymersome formation $(15 \mathrm{mM})$. The solution was irradiated at wavelengths ranging between $400 \mathrm{~nm}$ and $550 \mathrm{~nm}$ for $30 \mathrm{~min}$ using a mercury-xenon (Hg-Xe) lamp equipped with a broadband filter, and the osmolarity of the solutions was measured before and after the irradiation by the freezing point determination method. 


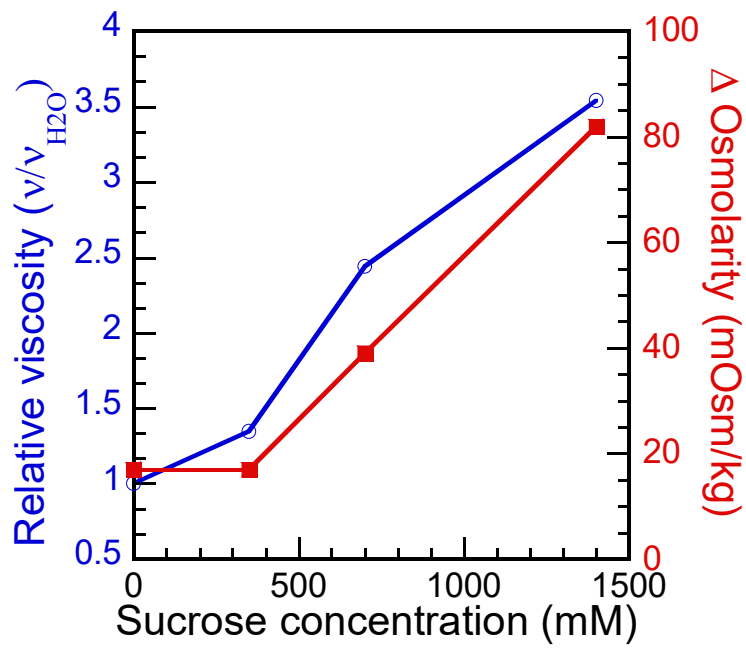

Figure S 2. Evolution of osmolarity increase upon irradiation correlated with the relative viscosity of $15 \mathrm{mM}$ calcein in increasing sucrose concentrations. Calcein solutions $(15 \mathrm{mM})$ with different sucrose concentrations were irradiated for $30 \mathrm{~min}$ in the $400-550 \mathrm{~nm}$ range with a $200 \mathrm{~W} \mathrm{Hg}$-Xe lamp equipped with a filter. Osmolarites were measured before and after irradiation. The difference in osmolarity after irradiation increases with the sucrose concentration, which determines the relative viscosity of the solution (ratio compared to pure water).

Solution osmolarity was found to significantly increase (up to $80 \mathrm{mOsm} / \mathrm{kg}$ ) with increasing sucrose concentration (Figure S 2). For a solution of $0.35 \mathrm{M}$ sucrose and $15 \mathrm{mM}$ calcein, there was an increase of $18 \mathrm{mOsm} / \mathrm{kg}$ after irradiation, whereas no increase was observed when irradiating pure sucrose solutions. Irradiation of calcein in the absence of sucrose led to the same increase of osmotic pressure, thus proving the non-interference of sucrose in the process. Then, we observed that increasing viscosity was correlated with a higher osmolarity difference after irradiation. Indeed, for $0.7 \mathrm{M}$ sucrose, the osmolarity increase was about $40 \mathrm{mOsm} / \mathrm{kg}$ and it doubled for $1.4 \mathrm{M}$ sucrose. We propose the interpretation that the viscosity of the solution has an impact on the diffusion of ROS and promotes degradation of the dye by lowering their diffusion away from the dye molecule.
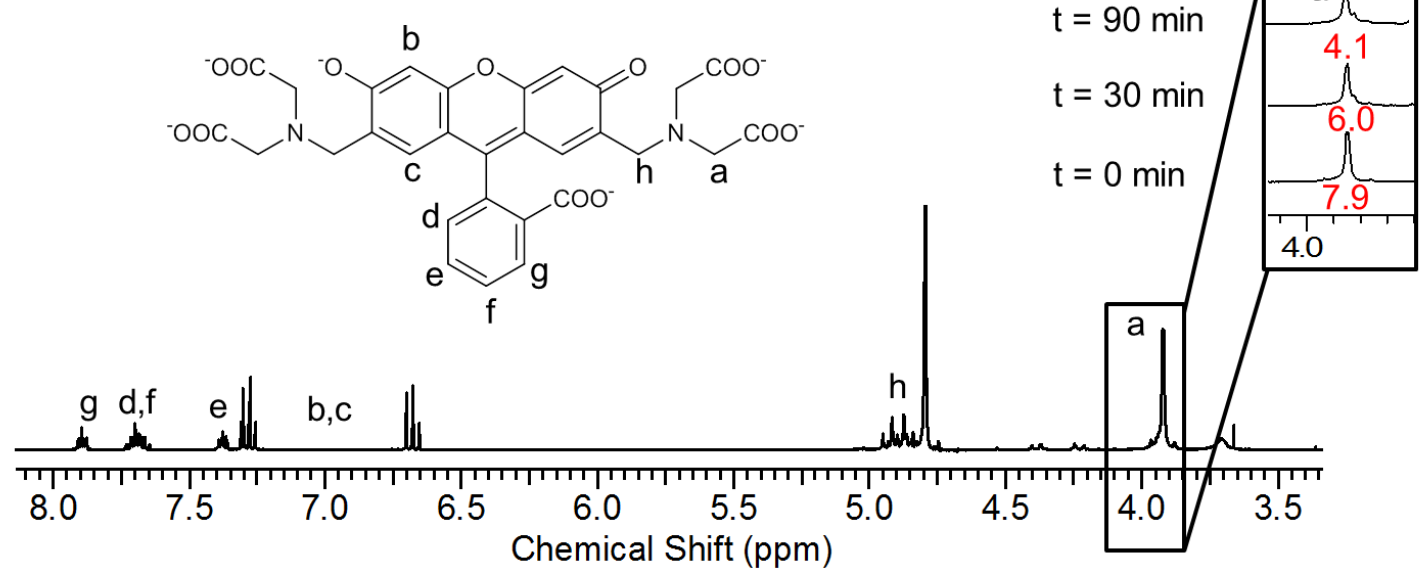

Figure S 3. ${ }^{1} \mathrm{H}$ NMR in $\mathrm{D}_{2} \mathrm{O}$ of calcein before and during irradiation ( $\mathrm{t}=30$ and $\left.90 \mathrm{~min}\right)$. Integration of proton a resonance $\left(-\mathrm{CH}_{2}-\mathrm{COOH}\right.$, $\delta=3.9 \mathrm{ppm})$ decreases with irradiation time indicating a probable cleavage of the $-\mathrm{CH}_{2}-\mathrm{COOH}$ arm mediated by ROS. Reference resonance for integration: aromatic proton $\mathbf{e}(\mathrm{H}, \delta=7.9 \mathrm{ppm})$. 
${ }^{1} \mathrm{H}$ NMR analysis of calcein in $\mathrm{D}_{2} \mathrm{O}$ during irradiation (Figure $\mathbf{S} 3$ ) proved that the changes in osmolarity were most certainly due to its degradation. Indeed, a decrease of the intensity of the resonance of the $\mathrm{CH}_{2}$ proton adjacent to the carboxylic moiety (a, $\left.\delta=3.93 \mathrm{ppm},-\mathrm{CH}_{2}-\mathrm{COOH}\right)$ was observed as a function of irradiation time. Moreover, the apparition of a peak at $8.46 \mathrm{ppm}$ after irradiation was consistent with the presence of formic acid, one of the probable degradation products. ${ }^{[8]}$ The control experiment, which consisted of irradiating solutions without calcein, did not show any change (Figure S 4 and Figure S 5). Additional control ${ }^{1} \mathrm{H}$ NMR experiments were performed in order to verify the non-interference of ROS with the membrane of the polymersomes (Figure S 6 and Figure S 7). Based on these results, as well as previous studies of ROS-mediated oxidation ${ }^{[8]}$, the suggested mechanism is based on a radical-mediated oxidation of calcein, leading to an increase of the internal osmotic pressure of the vesicle caused by the degradation products, arising through bond cleavage at the position labeled a on Figure S 3 (and also most likely at the two quasi-equivalent methylene groups adjacent to the carboxylate moiety).

The same experiments were performed with MB and showed that the dye underwent auto-degradation through the same process (Figure S 8 and Figure S 9).

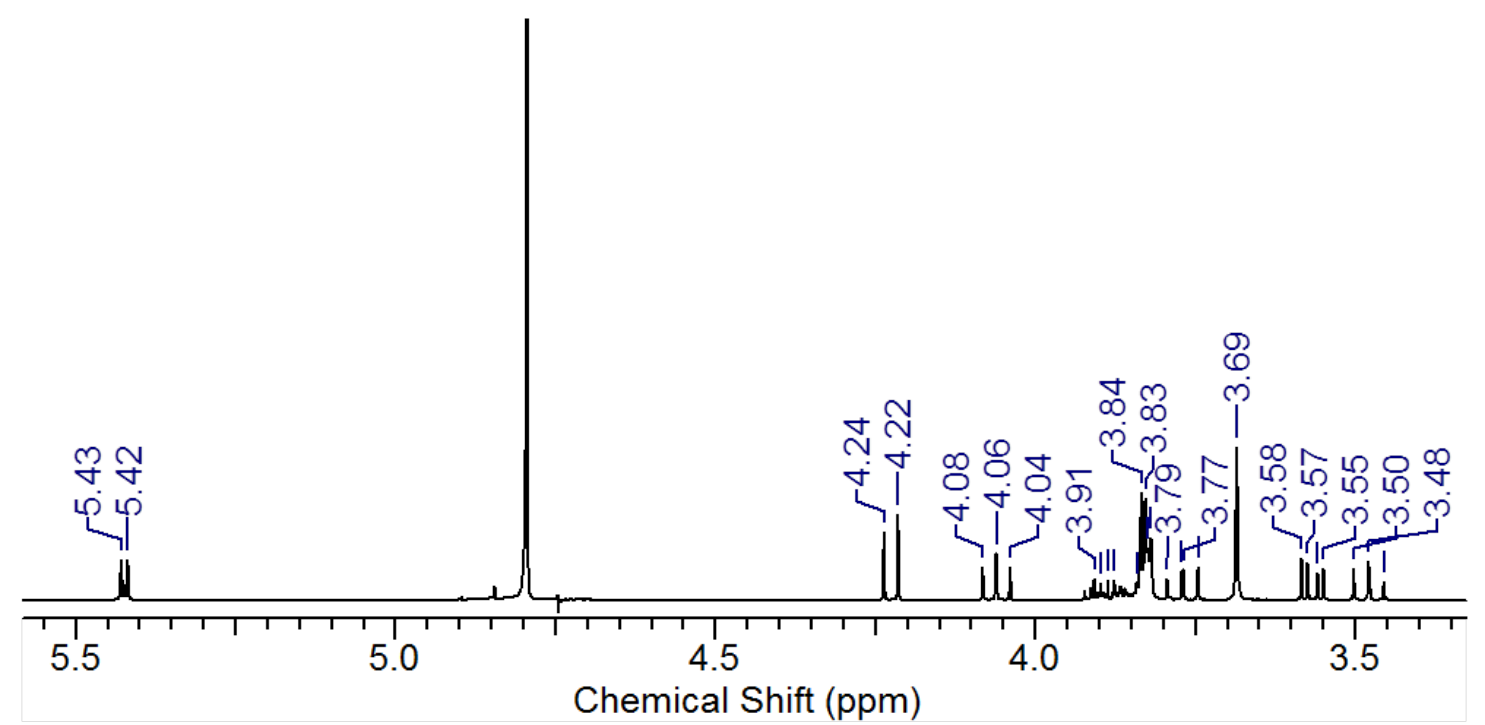

Figure S 4. ${ }^{1} \mathrm{H}$ NMR of sucrose. $\left(400 \mathrm{MHz}, \mathrm{D}_{2} \mathrm{O}\right), \delta(\mathrm{ppm}): 5.42(\mathrm{~d}, J=3.8 \mathrm{~Hz}, 1 \mathrm{H}), 4.22(\mathrm{~d}, J=8.6 \mathrm{~Hz}, 1 \mathrm{H}), 4.06(\mathrm{t}, J=8.6 \mathrm{~Hz}, 1 \mathrm{H}), 3.91-$ $3.86(\mathrm{~m}, 1 \mathrm{H}), 3.84(\mathrm{~m}, 1 \mathrm{H}), 3.81-3.78(\mathrm{~m}, 4 \mathrm{H}), 3.77(\mathrm{t}, J=10.1 \mathrm{~Hz}, 1 \mathrm{H}),, 3.69(\mathrm{~s}, 2 \mathrm{H}), 3.57(\mathrm{dd}, J=13.1 \mathrm{~Hz}, J=3.8 \mathrm{~Hz}, 1 \mathrm{H}), 3.48(\mathrm{t}, J=9.1$ $\mathrm{Hz}, 1 \mathrm{H})$. 


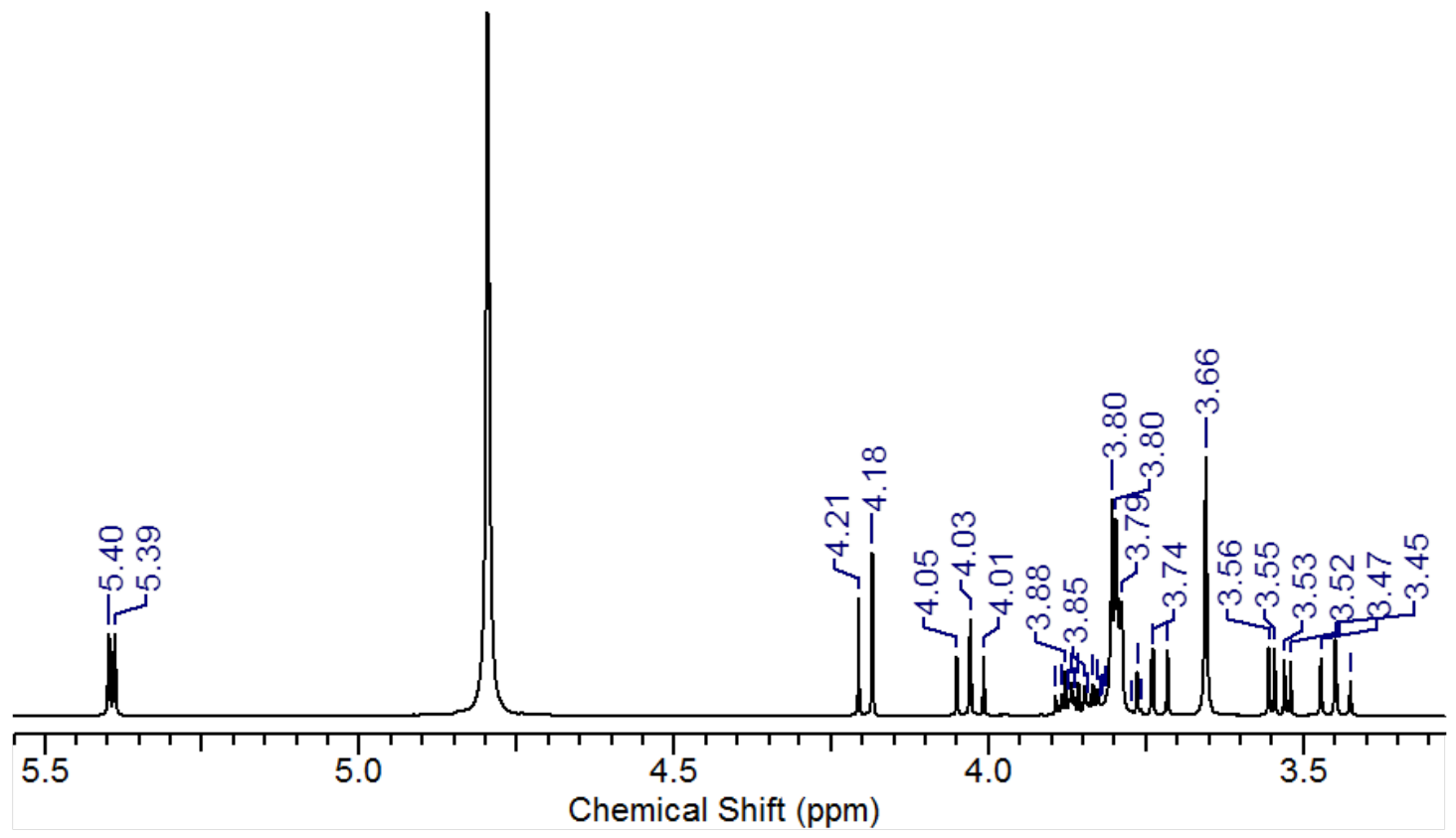

Figure S 5. ${ }^{1} \mathrm{H}$ NMR of sucrose after $30 \mathrm{~min}$ irradiation between 400 and $550 \mathrm{~nm}$. (400 MHz, $\left.\mathrm{D}_{2} \mathrm{O}\right), \delta(\mathrm{ppm}): 5.40(\mathrm{~d}, J=4 \mathrm{~Hz}, 1 \mathrm{H}), 4.21$ $(\mathrm{d}, J=8.6 \mathrm{~Hz}, 1 \mathrm{H}), 4.03(\mathrm{t}, J=8.5 \mathrm{~Hz}, 1 \mathrm{H}), 3.89-3.86(\mathrm{~m}, 1 \mathrm{H}), 3.84(\mathrm{~m}, 1 \mathrm{H}), 3.81-3.78(\mathrm{~m}, 4 \mathrm{H}), 3.74(\mathrm{t}, J=9.9 \mathrm{~Hz}, 1 \mathrm{H}), 3.66(\mathrm{~s}, 2 \mathrm{H})$, $3.55(\mathrm{dd}, J=9.9 \mathrm{~Hz}, J=3.8 \mathrm{~Hz}, 1 \mathrm{H}), 3.45(\mathrm{t}, J=9.3 \mathrm{~Hz}, 1 \mathrm{H})$.

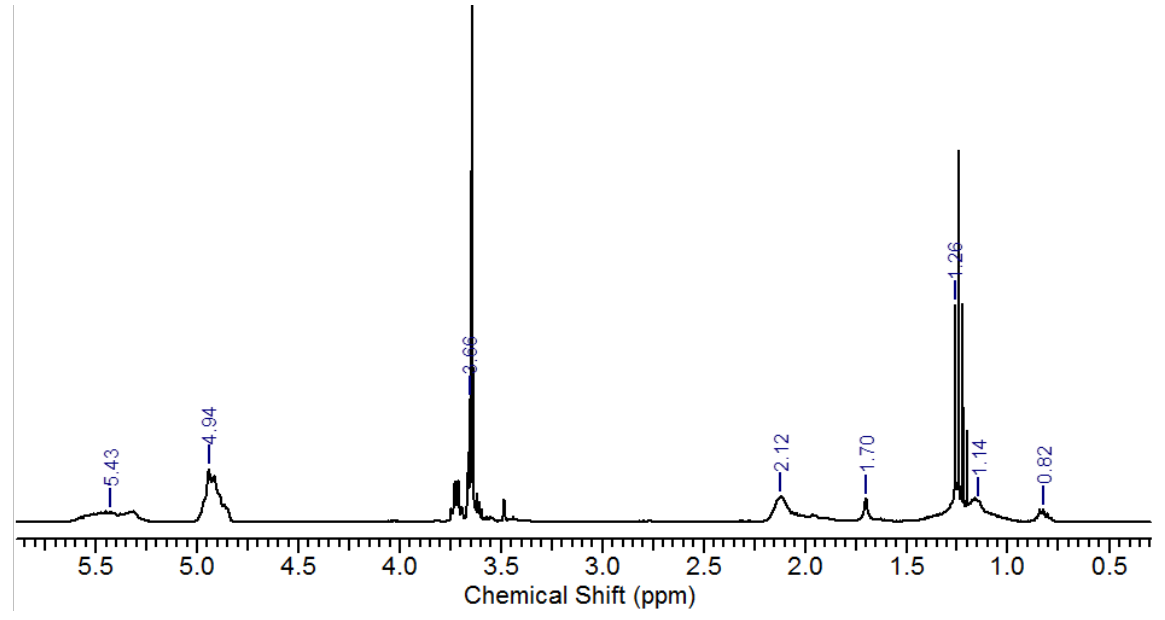

Figure S 6. ${ }^{1} \mathrm{H}$ NMR spectrum of $\mathrm{PBut}_{1.2}-b-\mathrm{PEO}_{0.6 .}\left(400 \mathrm{MHz}, \mathrm{CDCl}_{3}\right), \delta(\mathrm{ppm}): 5.65-5.30(\mathrm{~m}, 1 \mathrm{H}), 5.0-4.75(\mathrm{~m}, 2 \mathrm{H}), 3.64(\mathrm{~s}, 4 \mathrm{H})$, $1.25(\mathrm{~s}, 2 \mathrm{H})$. 


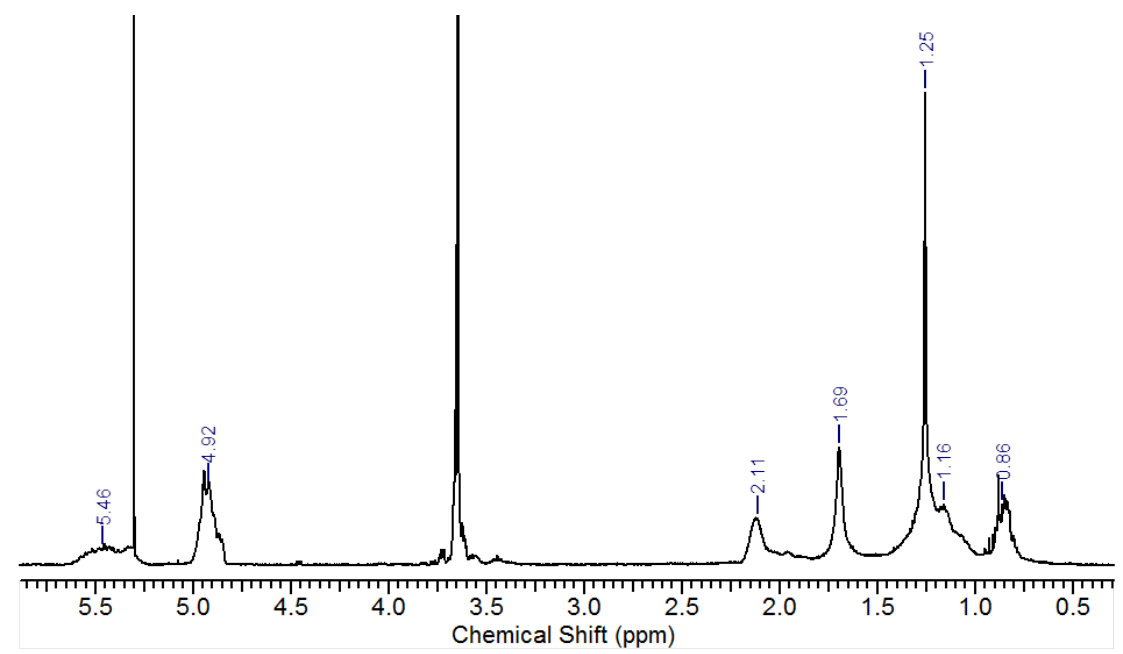

Figure S 7. ${ }^{1} \mathrm{H}$ NMR spectrum of $\mathrm{PBut}_{1.2}-b-\mathrm{PEO}_{0.6}$ after irradiation at $488 \mathrm{~nm}$ in presence of calcein. $\left.(400 \mathrm{MHz}, \mathrm{CDCl})_{3}\right), \delta(\mathrm{ppm}): 5.65-$ $5.30(\mathrm{~m}, 1 \mathrm{H}), 5.0-4.75(\mathrm{~m}, 2 \mathrm{H}), 3.64(\mathrm{~s}, 4 \mathrm{H}), 1.25(\mathrm{~s}, 2 \mathrm{H})$.

$\mathrm{PBut}_{1.2}-b-\mathrm{PEO}_{0.6}$ polymer LUVs of $100 \mathrm{~nm}$ diameter were formed by the thin film rehydration method. Briefly, a polymer film was dried in a round bottom flask and rehydrated overnight with $3 \mathrm{~mL}$ of a solution of $30 \mathrm{mM}$ calcein in $0.35 \mathrm{M}$ sucrose. The resulting suspension was extruded through a $100 \mathrm{~nm}$ polycarbonate filter (Avanti Polar Lipids). The calcein-loaded polymersomes were then irradiated at $488 \mathrm{~nm}$ overnight on an optical bench equipped with a $150 \mathrm{~W}$ Hg-Xe lamp and a monochromator. The polymer was recovered for NMR analyses by extraction with dichloromethane. 


\section{Evidence of ROS generation by methylene blue}

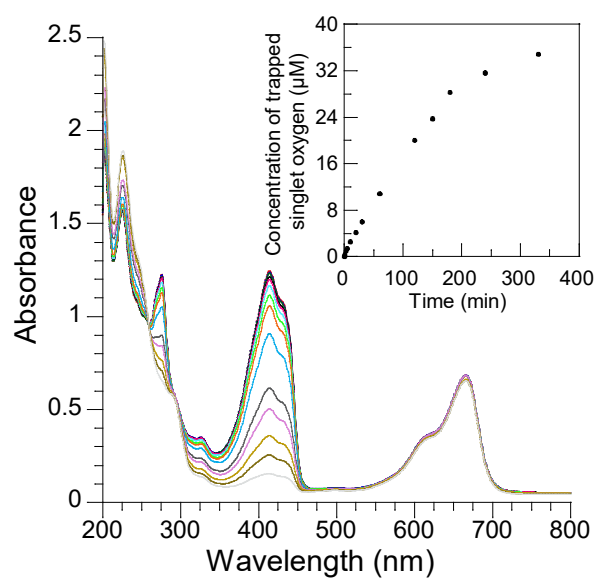

Figure S 8. Electronic absorption spectrum showing ROS photogeneration by methylene blue. UV-visible absorption spectrum of a solution of methylene blue $\left(\lambda_{\text {abs }}=500-700 \mathrm{~nm}\right)$ and singlet oxygen scavenger $\left(\lambda_{\text {abs }}=360-460 \mathrm{~nm}\right)($ ratio $1: 4)$ during irradiation at $633 \mathrm{~nm}$ and singlet oxygen consumption over time (inset). The decrease of the absorption band of the scavenger indicates the consumption of singlet oxygen generated during irradiation.
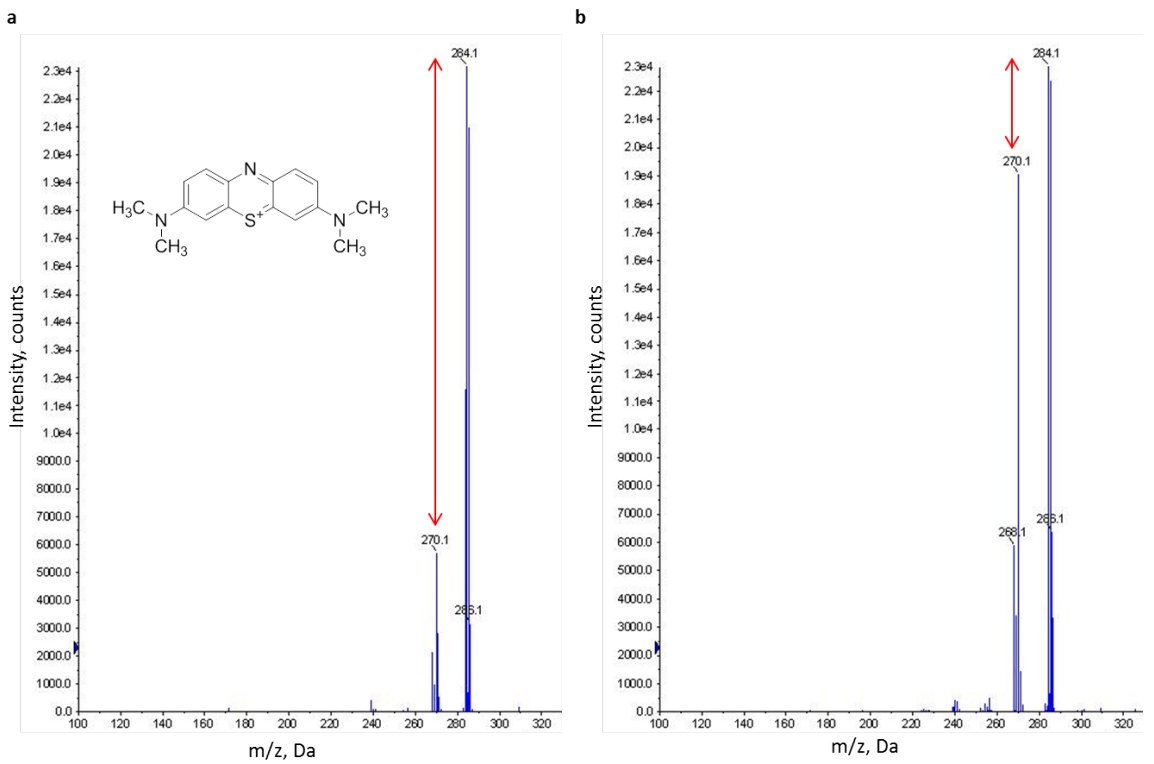

Figure S 9. ESI mass spectrum of methylene blue before and after overnight irradiation. A solution of 5 mM methylene blue in $\mathrm{D}_{2} \mathrm{O}$ was irradiated overnight at $633 \mathrm{~nm}$ and ESI analyses were performed a) before and b) after irradiation.

After irradiation of methylene blue the ESI spectrum shows an increase of the peak at $270.1 \mathrm{~m} / \mathrm{z}$ that corresponds to dye degradation. The same peak is present in a smaller proportion in the spectrum before irradiation because the sample was left unprotected from light a few hours before the analysis. 


\section{$\underline{\text { Vesicle swelling upon irradiation }}$}

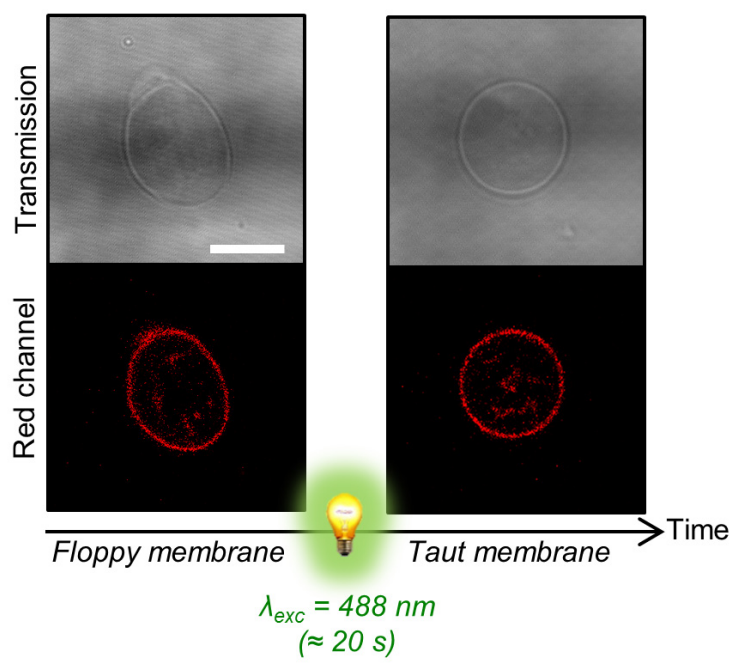

Figure S 10. Confocal observations of POPC GUVs loaded with $30 \mathrm{mM}$ calcein before and after irradiation at $488 \mathrm{~nm}$. The membrane is doped with L- $\alpha$-Phosphatidylethanolamine-N-(lissamine rhodamine B sulfonyl) to allow observation in the red channel. Upon irradiation, the vesicle membrane tightens without rupturing.

If the limited diffusion of water across the membrane is responsible for the explosion, using a much more permeable membrane should prevent it. In order to test this hypothesis, we formed 1-palmitoyl-2oleoyl-sn-glycero-3-phosphocholine (POPC) $\mathrm{GUVS}^{[1]}$, as lipidic membranes are known to exhibit tenfold higher permeability towards water than polymersomes. ${ }^{[9]}$ Figure $\mathbf{S} \mathbf{1 0}$ represents confocal images of a POPC GUV loaded with $30 \mathrm{mM}$ calcein before and after irradiation. For visualization in the red channel, the membrane was tagged with rhodamine. The images clearly show a floppy membrane before irradiation. After being excited $\left(\lambda_{\text {exc }}=488 \mathrm{~nm} ; 5 \%\right.$ laser intensity; $\left.20 \mathrm{~s}\right)$, the vesicle swelled without rupturing, even if higher laser intensity and/or illumination times were applied. These observations confirmed that water indeed diffused into the interior of such permeable lipidic vesicles to compensate for the osmotic imbalance, inducing its swelling, but without a rupture of the membrane. This scenario was confirmed by an additional experiment where a POPC GUV was partially aspired through a micropipette to evaluate its internal volume increase and hence the initial osmotic pressure increase upon calcein irradiation (Figure S 11). 


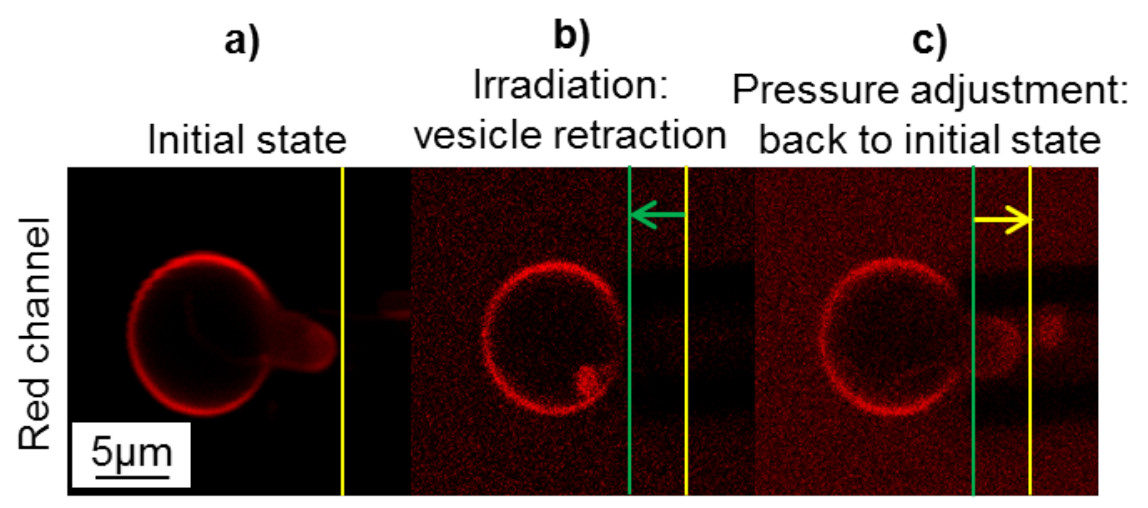

Figure S 11. Controlled membrane deformation of a phospholipid GUV by pressure adjustments through aspiration in a capillary. Confocal images of a $30 \mathrm{mM}$ calcein-loaded POPC GUV aspired inside a micropipette. The membrane is tagged with rhodamine for visualization in the red channel. Image a) shows the vesicle before irradiation. In image b), the vesicle is irradiated at $488 \mathrm{~nm}$ (calcein) and then (image c)) the pressure is adjusted (i.e. the level of the tank is decreased by a $55 \mathrm{~mm}$ height, corresponding to a negative pressure of $540 \mathrm{~Pa}$ ) to aspire the vesicle portion within the capillary back to its initial position $\boldsymbol{L}_{\mathrm{P}}=\mathbf{5} \mu \mathrm{m}$.

In the initial state (a), the vesicle has not been irradiated at $488 \mathrm{~nm}$ and the floppy membrane is rendered tauter by aspiration inside the capillary. When the vesicle is irradiated at $488 \mathrm{~nm}(\mathbf{b})$, calcein generates ROS that degrade the dye and induce an increase of the osmotic pressure. As the lipid membrane is permeable, water is able to enter the GUV to compensate for the osmotic imbalance. This results in a swelling of the vesicle and a retraction of the membrane tongue from the capillary by a length $\Delta L_{\mathrm{P}} \approx-4 \mu \mathrm{m}$. Using an equation introduced by Olbrich et al. for osmotically-swollen giant liposomes under micropipette aspiration, ${ }^{[10]}$ we can estimate the volume increase of liposomes caused by irradiation and ROS production: $\Delta V=-\pi D_{\mathrm{P}}\left(D_{\mathrm{V}}-D_{\mathrm{P}}\right) \Delta L_{\mathrm{P}} / 4=91 \mu \mathrm{m}^{3}$ for a vesicle of diameter $D_{\mathrm{V}}=10.8 \mu \mathrm{m}$ (initial volume $V_{\mathrm{i}}=660 \mu \mathrm{m}^{3}$ ) aspired in a pipette of diameter $D_{\mathrm{P}}=5 \mu \mathrm{m}$. The ratio $\Delta V / V_{\mathrm{i}} \approx 0.14$ can give an estimate of the osmotic pressure variation under illumination $\Delta C / C_{\mathrm{i}} \approx 0.14$ where the initial osmolarity is $C_{\mathrm{i}}=380 \mathrm{mOsm} \cdot \mathrm{kg}^{-1}$. Therefore we can estimate the osmolarity increase build up by light-induced ROS production and dye degradation at $\Delta C \approx 52 \mathrm{mOsm} \cdot \mathrm{kg}^{-1}$. When the pressure inside the capillary (c) was adjusted to pull the vesicle tether end back to its initial position, the lateral tension was raised up to $\sigma=1.3 \mathrm{mN} \cdot \mathrm{m}^{-1}$, a value still below the maximum lateral tension that a phospholipic GUV can withstand $\sigma_{\mathrm{lys}} \sim 10 \mathrm{mN} \cdot \mathrm{m}^{-1} \cdot{ }^{[10]}$ 


\section{Supplementary discussion: membrane pore opening dynamics}

The dynamics of pore opening were experimentally monitored and fitted with a theoretical model proposed by Mabrouk et al. in which they describe the curling of polymersome membranes induced by nucleation of a pore as a result of creation of an excess area on one of the two leaflets of the membrane through photo-isomerization of azobenzene moieties. ${ }^{[11]}$ We show that our system exhibits the same trends in pore opening dynamics although the initial constraint needed to induce membrane rupture is different in the two cases.

According to their model, the opening of a pore in the membrane can be compared with the curling rim instability of a bimetallic spring or an asymmetric elastic sheet. The dynamics of pore growth is governed by a transfer of the membrane surface elastic energy $S$ into viscous dissipation of the curling rim within the solution (either the inside solution of the polymersome if the rim curls inward, or the outside solution if the rim curls outwards, depending on whether the photoisomerizable groups are located on the outer or inner leaflet of the asymmetric block copolymer bilayer, respectively). In our case, Fig. 2a clearly shows the calcein outward flow through the pore (the fluorescence bursts arising from a suddenly unquenched signal by dye dilution), whereas the still quenched solution pocket trapped inside the rim is moving into the external medium. Our experiments are thus consistent with their model: the vesicles might also experience a change of spontaneous curvature due to the photo-osmotic phenomenon described to occur in the inner compartment. The pore opening dynamics has two regimes: ${ }^{[11]}$ constant velocity at the early stages, followed by a quasi-diffusive regime at longer times. More precisely, the effective diffusion constant of the rim (governing the rate of pore opening at long times) is expected to have a bulk (external) solution viscosity dependence when the rim is directed outwards (provoked by azobenzene groups in the inner leaflet in the previous case or internal osmotic pressure in the current case). In their initial publication, ${ }^{[11]}$ Mabrouk et al. gave an oversimplified form $r^{2}+2 r r_{c}=D_{\text {eff }} t$ that simply reduces to linear regime $r \sim\left(D_{\text {eff }} / 2 r_{c}\right) t$ at early stages and to pure

diffusive regime $r \sim \sqrt{D_{\text {eff }} t}$ at long stages. Subsequently, they considered a slightly modified form of the growth dynamics of a pore of radius $r$ at time $t$ as given by Equation (1) ${ }^{[12]}$ :

$$
2 r_{c} \dot{\mathrm{r}} / D_{\text {eff }}=2 /\left(1+\frac{r}{r_{c}}\right)^{\frac{1}{2}}-1 /\left(1+\frac{r}{r_{c}}\right)
$$

where $D_{\text {eff }}$ is the effective diffusion coefficient and $r_{\mathrm{c}}$ is defined as the critical pore radius, $r_{c}=\pi \kappa /\left(e S_{0}\right), \kappa$ being the bending modulus of the membrane, $e$ the membrane thickness and $S_{0}$ the stored elastic energy per unit area at initial time $t=0$ ). As the line tension (or line energy) of a pore in the membrane is usually expressed as $\tau=\kappa / 2 e$, we can also write $r_{c}=2 \pi \tau / S_{0}$ which represents well the balance between the 2 driving forces that determine the nucleation pore radius: on one side the elastic energy that tends to open up the pore $\left(\pi r_{c}^{2} S_{0}\right)$ and on the opposite the line energy that closes it $\left(2 \pi r_{c} \tau\right)$. 
The effective diffusion coefficient $D_{\text {eff }}$ is given by:

$$
D_{\text {eff }}=2 r_{c} S_{0} /(\eta \ln )=2 \pi \kappa /(e \eta \ln )=4 \pi \tau /(\eta \ln ) \approx 5 \tau / 2 \eta
$$

where $\eta$ represents the viscosity of the solution in which the membrane curls (the outside glucose solution in our case) and $\ln$ is a logarithmic term arising from the drag coefficient of a cylinder that is considered as constant: ${ }^{[11]} \ln =\ln (2 \pi r / L)+1 / 2 \approx 5$, and $4 \pi / \ln \approx 5 / 2$ (hence the simplified right term on Eq. (2).)

To compare our system with the aforementioned one, we prepared three different batches of giant vesicles with the emulsion-centrifugation technique (see experimental methods) with varying glucose concentrations. In each experiment, the concentration of the inner sucrose solution was adjusted to reach an osmotic equilibrium with the outer glucose solution. Calcein $(15 \mathrm{mM})$ was encapsulated within the vesicles to enable bursting under laser irradiation (488 nm, 5-10\% laser intensity). Movies of pore bursting were obtained at the highest achievable speed of the Leica SP5 resonant scanner (100 frames/s). The extracted frames of the explosions were processed with ImageJ freeware to track and measure membrane pore growth. For each glucose concentration, the experiment was repeated on an average of ten vesicles of equivalent sizes, and the results were plotted on a master curve (horizontal error bars represent standard deviations from different vesicles and horizontal error bars correspond to $\pm 5 \mathrm{~ms}$, i.e. half of the interval between successive frames) (Figure S 12).

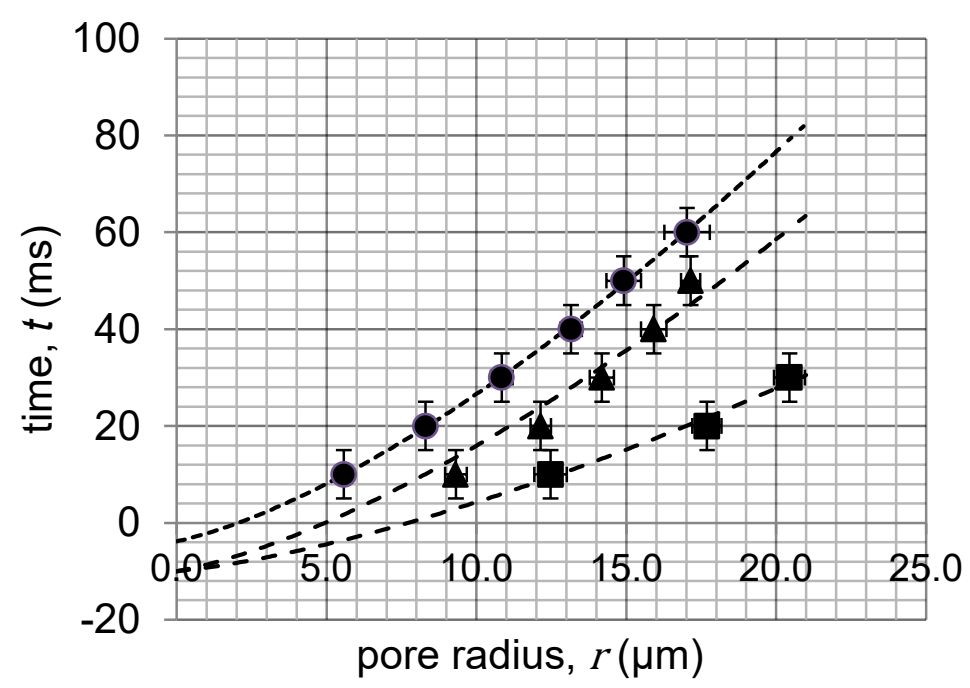

Figure S 12. Variations of pore opening dynamics in $\mathrm{PBut}_{2.5}-b-\mathrm{PEO}_{1.3}$ vesicles containing sucrose and calcein $15 \mathrm{mM}$ depending on viscosity of the external glucose solution. Pore radius as a function of time for three different glucose viscosities as averaged on several pore dynamics: $(\bullet) \eta=1.33 \mathrm{mPa} \cdot \mathrm{s},(\boldsymbol{\Delta}) \eta=2.46 \mathrm{mPa} \cdot \mathrm{s},(\boldsymbol{\bullet}) \eta=4.19 \mathrm{mPa} \cdot \mathrm{s}$. Equation (1) was used to fit the experimental data with two parameters: the critical pore radius $\left(r_{\mathrm{c}}\right)$ and the effective diffusion constant $\left(D_{\text {eff }}\right)$. The external glucose concentrations were chosen to balance osmolarity of the internal sucrose/calcein mixtures: $(\bullet)$ sucrose $20 \%$ in glucose $10 \%(0.6 \mathrm{M}),(\boldsymbol{\Delta})$ sucrose $50 \%$ in glucose $26 \%(1$ $475 \mathrm{M})$, ( $\mathbf{-}$ ) sucrose $70 \%$ in glucose $36 \%(2.06 \mathrm{M})$. Negative points on the time scale arise from the uncertainty about the initial time of pore nucleation (on the order of $10 \mathrm{~ms}$, i.e. the interval between successive frames). 
Glucose concentration

(M)

0.6

1.475

2.060
Glucose viscosity $\boldsymbol{\eta}$

(mPa·s)

1.33

2.46

4.19

\section{Apparent diffusion}

coefficient $D_{\text {eff }},\left(\mu \mathrm{m}^{2} \cdot \mathrm{s}^{-1}\right)$

1111

612

522

Table S 1. Variation of the apparent diffusion coefficient with external glucose solution viscosity (measured independently by rolling ball viscosimetry) as obtained by fitting the pore dynamics (Figure S1) with Eq. (1) with a constant critical radius $\boldsymbol{r}_{\boldsymbol{c}}=\mathbf{0} . \mathbf{3 8} \mu \boldsymbol{m}$. The calcein concentration is maintained at $15 \mathrm{mM}$.

From the fits derived from the experimental data (Eq. (1)), the effective diffusion coefficients $D_{\text {eff }}$ could be calculated by fixing the value of the critical radius $r_{\mathrm{c}}$ to $0.38 \mu \mathrm{m}$ for each viscosity. In agreement with the model proposed by Mabrouk et al., the diffusion coefficient is roughly inversely proportional to the viscosity of the solution into which the membrane curling rim advances (which determines the viscous losses) as in Eq. (2). The slight deviation from the perfect $\sim 1 / \eta$ dependency might be ascribed to a weak variation also of the line tension of the $\mathrm{PBut}_{2.5}-b-\mathrm{PEO}_{1.3}$ membrane with the sucrose and glucose concentrations, as with the reported modification of the mechanical properties ( $\kappa$ and thus $\tau$ ) for phospholipid bilayers exposed to high sugar concentrations. ${ }^{[13]}$ Regarding quantification, we can estimate the structural (hydrophobic thickness $e$ ) and mechanical (bending modulus $\kappa$ ) properties of the PBut $_{2.5}-b-\mathrm{PEO}_{1.3}$ membrane from their reported experimental values: $e=9.6 \mathrm{~nm}$ and $\kappa=24.7 \pm$ $11.1 k_{\mathrm{B}} T$, according respectively to cryo-TEM image analysis and micropipette measurements. ${ }^{[14]}$ Scaling laws versus the molar mass $M_{\mathrm{h}}$ of the hydrophobic block were proposed by Bermudez et al.: $:^{[15]}$ $e \sim M_{\mathrm{h}}{ }^{1 / 2}$ and $\kappa \sim K_{\mathrm{a}} e^{2} \sim M_{\mathrm{h}}$ since the area expansion elastic modulus was shown to be constant material property $K_{\mathrm{a}}=102 \pm 11 \mathrm{mN} / \mathrm{m}$ for all the PBut- $b$-PEO copolymer series. Therefore we deduce $e=6.7 \mathrm{~nm}$ and $\kappa=11.9 \pm 5.3 k_{\mathrm{B}} T$ for the less commonly used $\mathrm{PBut}_{1.2}-b-\mathrm{PEO}_{0.6}$ copolymer. From these values, we can obtain an estimate of the pore line tension: $\tau=\kappa / 2 e=3.7 \pm 1.7 \mathrm{pN}$ and $5.3 \pm$ $2.4 \mathrm{pN}$ for $\mathrm{PBut}_{1.2}-b-\mathrm{PEO}_{0.6}$ and $\mathrm{PBut}_{2.5}-b-\mathrm{PEO}_{1.3}$, respectively. Such line energies compare well to the value $\tau=4 \mathrm{pN}$ estimated by Mabrouk et al. for PBut- $b$-PEO copolymers, ${ }^{[11]}$ and are significantly lower than those measured on DPPC large liposomes at $46^{\circ} \mathrm{C}$ by Taupin et al. through the leakage of parametric probes under various hypotonic shocks (from $\tau=6.5 \mathrm{pN}$ for irreversible pores to $\tau=5.5-$ $8 \mathrm{pN}$ on sub-critical resealing pores $)^{[16]}$, on DOPC giant liposomes by Karatekin et al. ${ }^{[17]}$ through the closure dynamics of transient pores (from $\tau=6.9 \pm 0.4 \mathrm{pN}$ to $\tau=20.7 \pm 3.5 \mathrm{pN}$ depending on the supplier, and thus of purity, of DOPC), or by Levadny et al. ${ }^{[18]}$ by statistical analysis of the pore induction rate under micropipette pulling $(\tau=10.5 \pm 0.5 \mathrm{pN})$. Although the pore dynamics here are 
qualitatively equivalent to the experiment of Mabrouk et al. with photo-isomerizable liquid crystalline copolymers, in our case with $\mathrm{PBut}_{2.5}-b-\mathrm{PEO}_{1.3}$ the critical radius $r_{c}=0.38 \mu \mathrm{m}$ is much lower, which implies that the initial elastic tension is higher: $S_{0}=8.8 \cdot 10^{-2} \mathrm{mN} . \mathrm{m}^{-1}$. From the expression of the initial elastic tension $S_{0}=\frac{1}{2} \kappa\left(c_{0}\right)^{2}$, we get an estimate of the spontaneous curvature $c_{0}$ of the membrane, from which we deduce the spontaneous radius of curvature $\left(c_{0}\right)^{-1} \approx 24 \mathrm{~nm}$. Interestingly, this value is typically comparable to the smallest radius that large unilamellar vesicles (LUV) of a given copolymer can withstand from the rule-of-thumb $e / R_{\min } \approx 0.25$ as shown by Salva et al. after LUV rupture by hypertonic shocks, ${ }^{[19]}$ thus here $R_{\min } \approx 38 \mathrm{~nm}$ for $\mathrm{PBut}_{2.5}-b-\mathrm{PEO}_{1.3}$ polymersomes.

To interpret the different fates between liposomes and polymersomes exposed to increased internal osmotic pressure through dye irradiation at its maximum absorption wavelength, we propose a kinetic control of the membrane pore induction in these two different types of vesicles as opposed to a mere thermodynamic control sometimes put forward by several authors. ${ }^{[20,21]}$ To give quantitative values, the water permeability of monounsaturated phospholipids like POPC measured by the Evans micropipette aspiration method is $P \sim 30 \mu \mathrm{m} \cdot \mathrm{s}^{-1}$ and their lysis tension is $\sigma_{\mathrm{lys}} \sim 10 \mathrm{mN} \cdot \mathrm{m}^{-1},{ }^{[10]}$ whereas values for PBut $2.5^{-}$ $b-\mathrm{PEO}_{1.3}$ polymersomes are respectively $P \sim 3.1 \pm 1.6 \mu \mathrm{m} \cdot \mathrm{s}^{-1}$ from osmotic inflation experiments ${ }^{[22]}$ and $\sigma_{\text {lys }} \sim 16 \mathrm{mN} \cdot \mathrm{m}^{-1}$ from micropipette aspiration measurements ${ }^{[23]}$. In brief, polymersomes resist larger applied lateral stresses than fluid-phase liposomes and exhibit a higher toughness (i.e. a larger surface area below the curve of lateral tension versus membrane expansion coefficient), but they are 10 times less permeable to water, which is mainly ascribed to their thicker hydrophobic membrane $(\sim 6-10 \mathrm{~nm}$ as compared to $\sim 3-5 \mathrm{~nm}$ ). The lateral tension arising from the increased osmotic pressure relative to the external solution after dye photo-degradation can be estimated by the Laplace law of fluid interfaces $\Delta \pi=2 \sigma_{0} / R_{0}$ where $R_{0}$ is the initial vesicle radius and $\sigma_{0}$ is the lateral tension just before pore aperture. Converting the estimated osmolarity difference $\Delta \pi \approx 18 \mathrm{mOsm} \cdot \mathrm{kg}^{-1}$ into an osmotic pressure through the perfect gas law $\Delta \pi=\Delta c R T=4.5 \cdot 10^{4} \mathrm{~Pa}$ and using the Laplace law, we obtain a lateral tension $\sigma_{0} \sim 225 \mathrm{mN} \cdot \mathrm{m}^{-1}$ with $R_{0}=10 \mu \mathrm{m}$, well above the rupture tension $\sigma_{\text {lys }}$.

In the case of liposomes, the lateral tension on the membrane built up by the increase of solute concentration inside the vesicles can relax by internal volume reduction through outwards flow across "sub-critical" pores, i.e. holes in the bilayer that have a size insufficient to expand (below the critical radius $r_{c}$ ) but nevertheless contribute to increase permeability. Their existence has been evidenced more than four decades ago by the pioneering work of Taupin et al. ${ }^{[16]}$ using electron paramagnetic resonance (EPR) probes. These authors also demonstrated that the frequency of vesicle leakage (i.e. inverse of mean leakage time) through transient pores for a given solute over-concentration inside the vesicles is inversely proportional to $\tau^{2}$, the square of line tension. This mechanism of transient or "pulsatile" pore formation relaxing the pressure in response to an osmotic shock, classical for liposomes, ${ }^{[24]}$ can 
certainly not work in the case of polymersomes due to their too low line energy $\tau$ compared to liposomes, not sufficient to reseal the membrane once a pore is nucleated. This is why for the same osmotic pressure imposed (same solutes encapsulated and same conditions of illumination), polymersomes leak much more slowly than liposomes, and thus they stay longer in a taut state without relaxing their lateral tension, until they eventually burst irreversibly. The osmotically driven vesicle rupture triggered by illumination described in this article corresponds to a kinetic control of rupture, the lower permeability of polymersomes letting them for longer in a tense state and maximizing their probability to undergo rupture with less possibility of resealing (since the driving force for pore closure is $\tau$ ). 


\section{Additional figures}

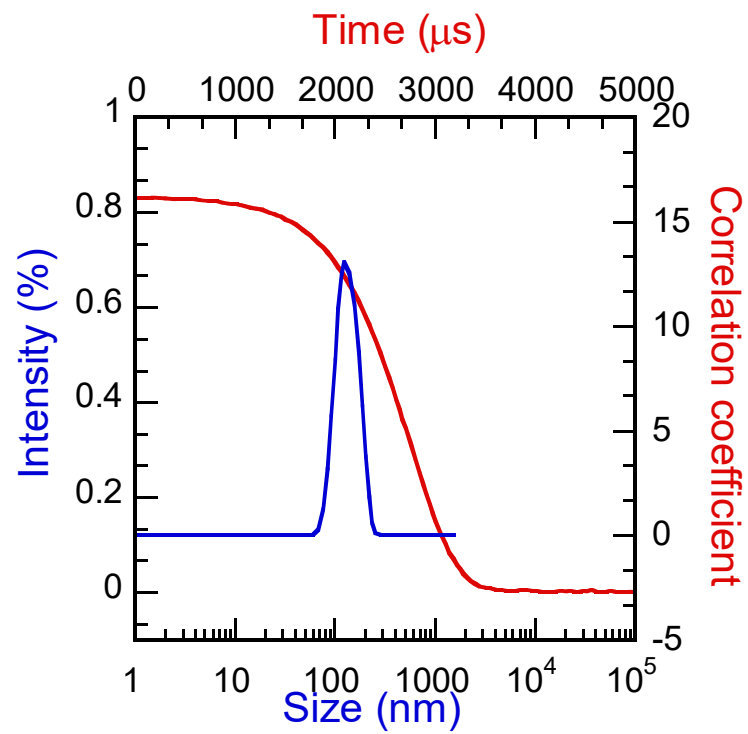

Figure S 13. DLS measurement of a solution of extruded $100 \mathrm{~nm}$ DPPC liposomes.

Time $(\mu \mathrm{s})$

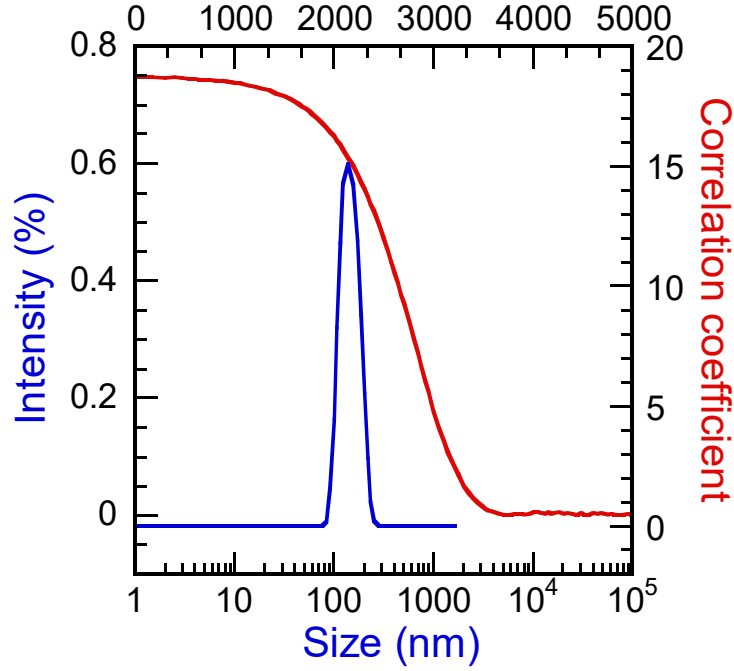

Figure S 14. DLS measurement of a solution of extruded $100 \mathrm{~nm} \mathrm{PBut}_{1.2}-b-\mathrm{PEO}_{0.6}$ polymersomes. 


\section{References}

[1] A. Weinberger, F.-C. Tsai, G. H. Koenderink, T. F. Schmidt, R. Itri, W. Meier, T. Schmatko, A. Schröder, C. Marques, Biophys. J. 2013, 105, 154-164.

[2] M. Marguet, L. Edembe, S. Lecommandoux, Angew. Chem. Int. Ed. 2012, 51, 1173-1176.

[3] W. A. Velema, J. P. van der Berg, W. Szymanski, A. J. M. Driessen, B. L. Feringa, ACS Chem. Biol. 2014, 9, 1969-1974.

[4] B. Karami, M. Kiani, J. Chin. Chem. Soc. 2014, 61, 213-216.

[5] C. Beghetto, C. Renken, O. Eriksson, G. Jori, P. Bernardi, F. Ricchelli, Eur. J. Biochem. 2000, 267, 5585-5592.

[6] D. Arian, E. Cló, K. V. Gothelf, A. Mokhir, Chem. Weinh. Bergstr. Ger. 2010, 16, $288-295$.

[7] M. Bancirova, Luminescence 2011, 26, 685-688.

[8] T. F. Zhu, J. W. Szostak, J. Syst. Chem. 2011, 2, 4.

[9] J.-F. L. Meins, O. Sandre, S. Lecommandoux, Eur. Phys. J. E 2011, 34, 1-17.

[10] K. Olbrich, W. Rawicz, D. Needham, E. Evans, Biophys. J. 2000, 79, 321-327.

[11] E. Mabrouk, D. Cuvelier, F. Brochard-Wyart, P. Nassoy, M.-H. Li, Proc. Natl. Acad. Sci. 2009, 106, 7294-7298.

[12] E. Mabrouk, Vésicules Polymères (Polymersomes) Stimulables, Paris 6, 2010.

[13] R. Dimova, Adv. Colloid Interface Sci. 2014, 208, 225-234.

[14] H. Bermúdez, D. A. Hammer, D. E. Discher, Langmuir 2004, 20, 540-543.

[15] H. Bermudez, A. K. Brannan, D. A. Hammer, F. S. Bates, D. E. Discher, Macromolecules 2002, $35,8203-8208$.

[16] C. Taupin, M. Dvolaitzky, C. Sauterey, Biochemistry 1975, 14, 4771-4775.

[17] R. Salva, J.-F. Le Meins, O. Sandre, A. Brûlet, M. Schmutz, P. Guenoun, S. Lecommandoux, ACS Nano 2013, 7, 9298-9311.

[18] E. Karatekin, O. Sandre, H. Guitouni, N. Borghi, P.-H. Puech, F. Brochard-Wyart, Biophys. J. 2003, 84, 1734-1749.

[19] V. Levadny, T. Tsuboi, M. Belaya, M. Yamazaki, Langmuir 2013, 29, 3848-3852.

[20] M. A. S. Karal, M. Yamazaki, J. Chem. Phys. 2015, 143, 81103.

[21] J. C. Shillcock, U. Seifert, Biophys. J. 1998, 74, 1754-1766.

[22] A. Carlsen, N. Glaser, J.-F. Le Meins, S. Lecommandoux, Langmuir 2011, 27, 4884-4890.

[23] P. P. Ghoroghchian, J. J. Lin, A. K. Brannan, P. R. Frail, F. S. Bates, M. J. Therien, D. A. Hammer, Soft Matter 2006, 2, 973-980.

[24] D. Popescu, Proc. Romanian Acad. 2010, 11, 108-115. 